\title{
Strengthening postnatal care services including postpartum family planning in Kenya
}

Annie Mwangi

Population Council

Charlotte E. Warren

Population Council

Nancy Koskei

Holly Blanchard

Follow this and additional works at: https://knowledgecommons.popcouncil.org/departments_sbsr-rh

Part of the Demography, Population, and Ecology Commons, International Public Health Commons, Maternal and Child Health Commons, and the Women's Health Commons How does access to this work benefit you? Let us know!

\section{Recommended Citation}

Mwangi, Annie, Charlotte E. Warren, Nancy Koskei, and Holly Blanchard. 2008. "Strengthening postnatal care services including postpartum family planning in Kenya," FRONTIERS Final Report. Washington, DC: Population Council. 


\title{
Strengthening Postnatal Care Services Including Postpartum Family Planning in Kenya
}

\author{
Frontiers in Reproductive Health, Population Council \\ Annie Mwangi \\ Charlotte Warren
}

\author{
ACCESS-FP, Jhpiego \\ Nancy Koskei \\ Holly Blanchard
}

June 2008

This study is made possible by the generous support of the American people through the United States Agency for International Development (USAID) under the terms of Cooperative Agreement Number HRN-A-00-98-00012-00 and Subproject number 580053108.

The contents are the responsibility of the FRONTIERS Program and do not necessarily reflect the views of USAID or the United States Government.
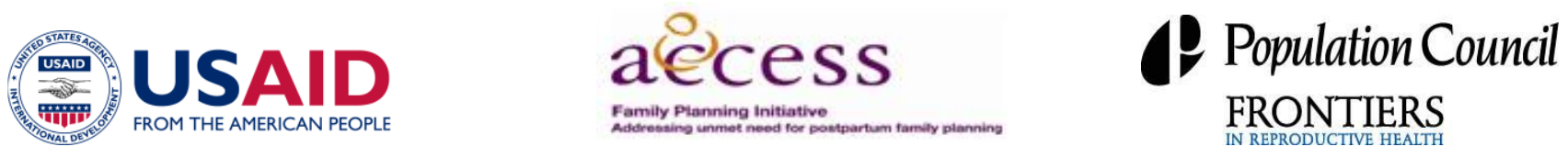


\section{Acknowledgments}

We would like to thank all those who made this operations research possible. Work of this nature would not have been possible without full support from the Ministry of Health, Division of Reproductive Health, Dr Josephine Kibaru and Mary Gathitu. In addition support from the Provincial Health Management Team, Eastern Province, specifically the Provincial Reproductive Health Coordinator Team, Dr Jacinta Njagi, The Embu District Medical Officer of Health, Dr. Enos Okumu Masini, the District Reproductive Health Coordinator, Florence Karanja, and the District Public Health Officer, Peris Nyaga.

Special thanks go to Rosemary Kimunya and Dorothy Andere (ACCESS FP) who carried out the training. We are also grateful for the technical support received from Ian Askew (FRONTIERS) and Catherine McKaig (ACCESS- FP).

Our appreciation goes to the research assistants that formed field teams to collect data especially those public health technicians who assisted in moving around the community. Special thanks go to all the postpartum women who participated in the study; without them the research would not have been possible. 


\section{Contents}

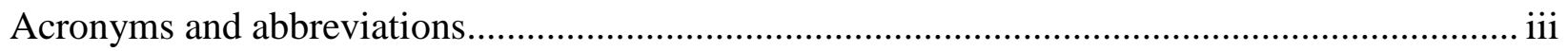

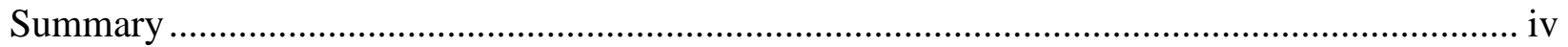

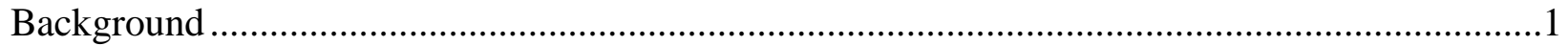

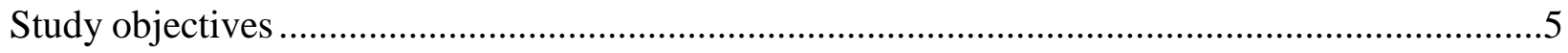

Design and implementation of the strengthened postpartum services package...........................5

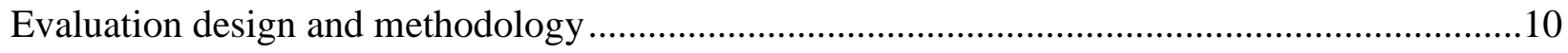

Key variables and indicators for objectives two and three ................................................. 10

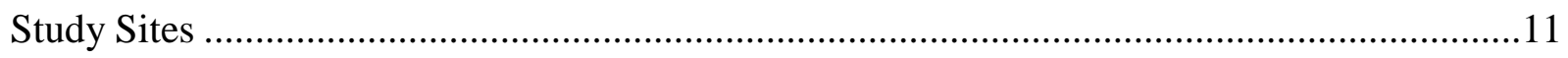

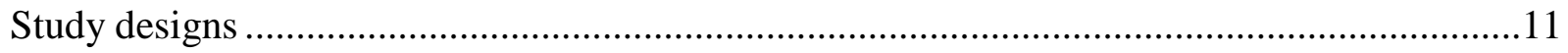

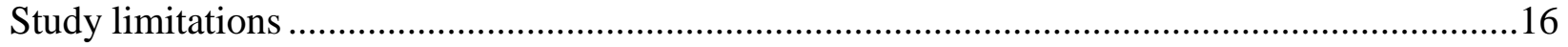

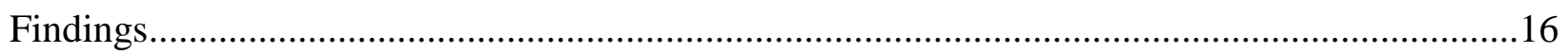

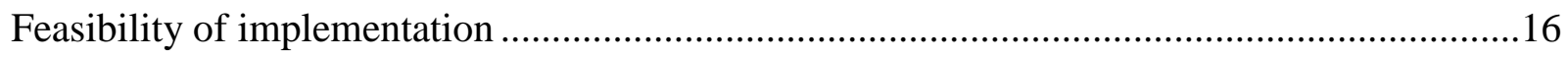

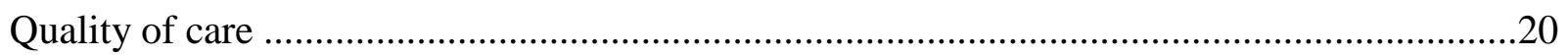

Fertility and family planning behaviors at six months .................................................27

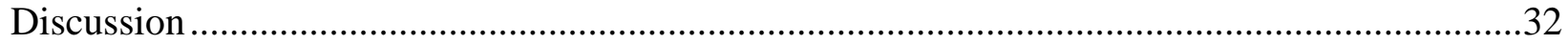

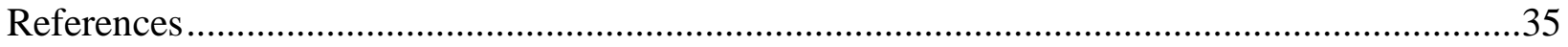




\section{ACRONYMS AND ABBREVIATIONS}

$\begin{array}{ll}\text { AFASS } & \text { Acceptable Feasible, Affordable, Safe and Sustainable } \\ \text { AIDS } & \text { Acquired Immuno Deficiency Syndrome } \\ \text { ANC } & \text { Antenatal Care } \\ \text { ARV } & \text { Anti retro viral } \\ \text { COC } & \text { Combined oral contraceptive } \\ \text { CS } & \text { Caesarean Section } \\ \text { CT } & \text { Counseling and Testing } \\ \text { DHMT } & \text { District Health Management Team } \\ \text { DRH } & \text { Division of Reproductive Health } \\ \text { FANC } & \text { Focused Antenatal Care } \\ \text { FP } & \text { Family Planning } \\ \text { HIV } & \text { Human Immuno-deficiency Virus } \\ \text { HTSP } & \text { Healthy Timing and Spacing of Pregnancy } \\ \text { IEC } & \text { Information, Education and Communication } \\ \text { IUD } & \text { Intra Uterine Contraceptive Device } \\ \text { KDHS } & \text { Kenya Demographic Health Survey } \\ \text { LAM } & \text { Lactational Amenorrhea Method } \\ \text { MCH } & \text { Maternal and Child Health } \\ \text { MOH } & \text { Ministry of Health } \\ \text { NASCOP } & \text { National AIDS and STDs Control Program } \\ \text { NHSSP } & \text { National Health Sector Strategic Plan } \\ \text { PGH } & \text { Provincial General Hospital } \\ \text { PHT } & \text { Public Health Technician } \\ \text { PMTCT } & \text { Prevention of Mother to Child Transmission } \\ \text { PNC } & \text { Postnatal care } \\ \text { PPH } & \text { Postpartum Hemorrhage } \\ \text { POP } & \text { Progestin only pill } \\ \text { PP } & \text { Postpartum } \\ \text { SMDP } & \text { Safe Motherhood Demonstration Project } \\ \text { STI } & \text { Sexually Transmitted Infection } \\ \text { RH } & \text { Reproductive health } \\ \text { WHO } & \text { World Health Organization } \\ & \end{array}$




\section{SUMMARY}

To improve the health and survival of mothers and infants in the postnatal period, the Ministry of Health $(\mathrm{MOH})$ in Kenya increased both the recommended timing and content of postnatal services a women and her infant should receive to at least three assessments within the first six weeks after childbirth. The feasibility and acceptability of providing postnatal care at these times has not been evaluated, however, and most providers are not aware of this change in policy or how to implement it. The objectives of the study were develop and introduce a strengthened postnatal care package into one hospital and four health centers in one district, to document the feasibility, acceptability and quality of care of the strengthened postnatal care, and to evaluate the effectiveness of the postnatal package on women's reproductive health behaviors. The study was implemented jointly by the Population Council's Frontiers in Reproductive Health (FRONTIERS) project and by Jhpiego's ACCESS-FP project, both funded by USAID.

The study was conducted in Embu district, Eastern Province, between 2006 and 2008. The study used a pre-post intervention design for assessing quality of care received within the facilities and compared stratified samples of postpartum women recruited and interviewed following childbirth and again six months later before and after introduction of the intervention. For the quality of care assessment, data were collected through interviews with health care providers, structured observations of client - provider interactions during the postnatal consultations and a facility inventory for assessing availability of equipment, drugs, family planning commodities and supplies. Postpartum women were recruited and interviewed following childbirth on the postnatal ward in Embu Provincial General Hospital and interviewed again in their community after six months.

A postnatal care - family planning (PNC-FP) orientation package for providers was developed by ACCESS-FP, DRH and FRONTIERS. This incorporated relevant maternal and newborn health care services in the postnatal period with a specific focus on postpartum family planning. Job aids were also produced. The three day orientation training included staff from the maternity and $\mathrm{MCH}$ - FP units from the four health facilities, as well as provincial and district RH trainers/supervisors. In total, 73 health care providers were oriented in the PNC - FP package, as well as in the use of a new postnatal register recently released by the MOH. Regular supportive supervision visits were made during the intervention period to reinforce application of the package. The key findings were as follows:

Facilities were prepared or needed minimal adjustments to provide strengthened PNC and postpartum family planning services.

Provider knowledge improved in maternal and newborn care. Providers were more likely to report discussing FP with postpartum women at 48 hours and at six weeks. It is important to note that provider knowledge in several components was weaker than anticipated before the intervention and that although there were significant improvements, gaps remained at endline in that need further attention.

Overall quality of care improved, especially in counseling for family planning and in ensuring the mother had a physical checkup during the 48 hour, two week and six week consultations.

Substantial improvements in uptake of family planning postpartum were noted.

Significantly more women were observed accepting an FP method during the six week 
consultation after the intervention; specifically the IUD and LAM, injectables and female sterilization rates were also higher among the intervention group (although these differences were not statistically significant).

Providers are both satisfied and confident with the care they give to postpartum women. Health system gaps and insufficient numbers of health providers that are commonly found throughout Kenya inhibited full implementation of the intervention and were not inherent to the approach itself.

Postpartum women are willing to come for the increased number of postnatal checkups and to bring their infants; they were also significantly more likely to recommend the services to a friend. Significantly more women and their infants made their first visit to the PNC within 14 days of delivery after the intervention. Infants are still seen by health providers twice as often as their mothers during the six months postpartum period, suggesting that mothers and providers still perceive PNC as being more important for the infant than the mother.

Postpartum women now start using FP methods much earlier (i.e. within two months) after the intervention. This may be attributable to women being more likely to report having been informed about a choice of family planning methods at several times during ANC and through to six months postpartum. After the intervention, there was an increase in the use of FP methods by six months and a decrease in women with an unmet need for family planning (although neither was statistically significant).

The PNC-FP package developed and tested through this project is acceptable to both clients and providers and can be introduced fairly easily through a three-day orientation training and enhanced through supportive supervision. The package of services provided for women proved effective in enhancing the quality of postpartum family planning and routine postnatal care. Improvements in the quality of care regarding complications, although significant, need further attention as the level of skills found at baseline were lower than anticipated when the training package was developed. To raise the standard of care further, future use of this training and supervision package as a standard protocol for the $\mathrm{MOH}$ in Kenya or elsewhere should include a clinical skills component for maternal and neonatal complications.

Drawing from findings from the study, it can be recommended that:

- Further consultations be held with key actors to ensure institutionalization and standardization of PNC and postpartum family planning. This should include integration or linkages with PMTCT and STI services and incorporating or updating curricula of preservice training institutions and professional bodies.

- Community linkages be strengthened to create awareness about the new postnatal consultations and services, including co-opting critical actors such as male partners and mothers in law, community leaders and health committees, community midwives, and community health workers.

- Postnatal care be scaled-up through training providers in a comprehensive package of skills and care for the mother and her infant, which includes family planning. 


\section{BACKGROUND}

Most deaths of mothers and newborns occur very soon after delivery - over 60 percent of maternal deaths occur in the first 48 hours after childbirth (WHO 2005). For many women in eastern and southern Africa the postnatal period is a time of increased susceptibility to HIV and STIs (McIntyre 2005; Dept of Health, South Africa 2003). There is also increasing evidence that maternal deaths related to HIV are rising (Gray and McIntyre 2005; Lewis 2004). Three quarters of newborn deaths occur in the first week and of those, two thirds occur in the first 24 hours (Lawn et al 2005). Although HIV infection in the mother will influence the baby's survival, practically all neonatal deaths in the first month of life are due to non-HIV causes (e.g. asphyxia, sepsis and prematurity), highlighting the need to address the quality of basic maternal and newborn care. It has been estimated that if 90 percent of babies and mothers received routine postnatal care (PNC) 10 to 27 percent of newborn deaths could be averted (Warren, Daly, Touré and Mongi 2006). Inter-pregnancy intervals of less than 18 months and more than 59 months are significantly associated with increased risk of adverse perinatal outcomes (Conde-Agudelo et al 2006). The WHO Technical Consultation on Birth Spacing (WHO, 2005) reported that for the healthiest outcome for mother and baby, couples should wait at least two years after the birth of their last infant before they try to conceive again to reduce risks of adverse maternal, perinatal and infant outcomes.

In Kenya the majority of women (90 percent) attend antenatal care at least once and 52 percent attend four or more times (KDHS 2003). Skilled health personnel assist 42 percent of births, with almost all these occurring in a facility. The remainder is attended by relatives or friends ( 22 percent), Traditional Birth Attendants (TBAs) (28 percent) or no-one (eight percent). The maternal mortality ratio is 414 per 100,000 live births, the neonatal mortality rate is $33 / 1000$ live births and 77 infants out of 1000 live births die before their first birthday. Eighty-one percent of women delivering at home do not receive a postnatal check up, and only 12 percent of those women who do receive postnatal care are seen within six days of the birth. It is assumed that women who deliver in a health facility receive postnatal care, but this is not necessarily the case and is not measured in demographic health surveys.

The early identification of postnatal complications for both mother and baby can reduce maternal and newborn morbidity and mortality. However few African countries, including Kenya, have mechanisms in place to ensure that both women and their infants are assessed during the postpartum period. Evidence suggests that there are some "crucial" moments when contact with the formal health system during the postpartum period by skilled attendants could be instrumental in identifying and responding to needs and complications after childbirth: the first few hours after birth (whether at home or in a health facility), between three to seven days, and at six weeks (Lawn and Kerber 2006; Narayanan 2004).

In Kenya, correct care during the postnatal period for mother and baby is outlined in the National Guidelines for Quality Obstetrics and Perinatal Care (2004). However these guidelines lack specific recommendations on postnatal care for both mother and infant from the first six hours postpartum to six weeks after delivery. The Department of Reproductive Health's (DRH) Safe 
Motherhood Program outlines eight pillars ${ }^{1}$ of safe motherhood and complements the life cycle approach building on the concept of the continuum of care.

In response to findings from the DFID-funded Safe Motherhood Demonstration Project (SMDP) in Western Province Kenya (2004) ${ }^{2}$, the DRH, National AIDS and STI Control Program (NASCOP), University of Nairobi, Population Council and other stakeholders came together in 2004 to develop guidelines for improving postpartum care. Three consultations were recommended for the mother and baby: within 48 hours on the postnatal ward before discharge; a second assessment one to two weeks following delivery in the MCH-FP clinic; and again at six weeks (DRH 2005). A postpartum register was developed and piloted in 2005 in an effort to document and measure postpartum care, which was subsequently revised and updated during a wider review of antenatal care (ANC), delivery, family planning (FP) and child welfare registers by the Department of Health Information Management Service in 2006. The DRH is currently disseminating these updated registers to all districts.

Inclusion of the pre-discharge package of care (within 48 hours) assures that the mother and infant are evaluated by a health provider before they leave the postnatal ward, or are seen soon after birth if delivered at home. This consultation presents an opportunity to identify and address problems, to identify and act on any danger signs, to counsel on essential care, and to counsel and provide appropriate FP methods. The second postnatal consultation within $7-14$ days provides another opportunity to assess infant feeding and essential obstetric and newborn care, as well as to reassure the mother and to re-iterate FP messages. Similarly, by strengthening the content of the six week consultation, more infants can be immunized and more women have access to FP counseling and subsequent uptake of a contraceptive method.

The national contraceptive prevalence rate has stagnated at 39 percent and many women have limited access to FP during the immediate postpartum period. More than 27 percent of 20-29 year old women had less than two years between their last two pregnancies (KDHS 2003). According to the 2003 DHS, in Kenya, 23 percent of births are at intervals of less than 24 months; these short intervals increase the risk of adverse perinatal outcomes. Many of these births are unintended. An analysis of the 2003 Kenya DHS found that 68 percent of postpartum women had an unmet need for FP during the first year (Borda 2006), with only 23 percent using a method. Integrating FP with other health services during and after pregnancy can help increase access to and use of contraception, thereby reducing unmet need and preventing unintended pregnancies.

Throughout the world, many women use the return of their menstrual period as a signal to begin using contraception, yet the return of menses may indicate that fertility returned several weeks before, thus leaving up to 10 percent of women at risk of becoming pregnant before their menses resume (Becker and Ahmed 2001). The Lactational Amenorrhea Method (LAM) is a first short term contraceptive method for women who are fully breastfeeding, who have not resumed their period, and who are less than six months postpartum; when practiced correctly it can be more than 98 percent effective. In addition to delaying a subsequent pregnancy, exclusive

1 The eight pillars are: focused antenatal care, essential obstetric care, clean and safe delivery, newborn care, targeted postpartum care, family planning, PMTCT and postabortion care.

$2 \quad$ Implemented by the Ministry of Health, University of Nairobi and Population Council. 
breastfeeding also contributes to improved child survival. WHO promotes the benefits of exclusive breastfeeding among HIV positive women where supplemental feeding is not acceptable, feasible affordable, safe or sustainable (WHO 2006). However, providers in Kenya have received mixed messages about the benefits of exclusive breastfeeding for HIV positive women and many are not confident about the efficacy or criteria of LAM as contraception. Figure 1 outlines the contraceptive method choices available for postpartum women dependent of length of time postpartum and breastfeeding status.

\section{Figure 1: FP methods appropriate for women in the extended postpartum period}

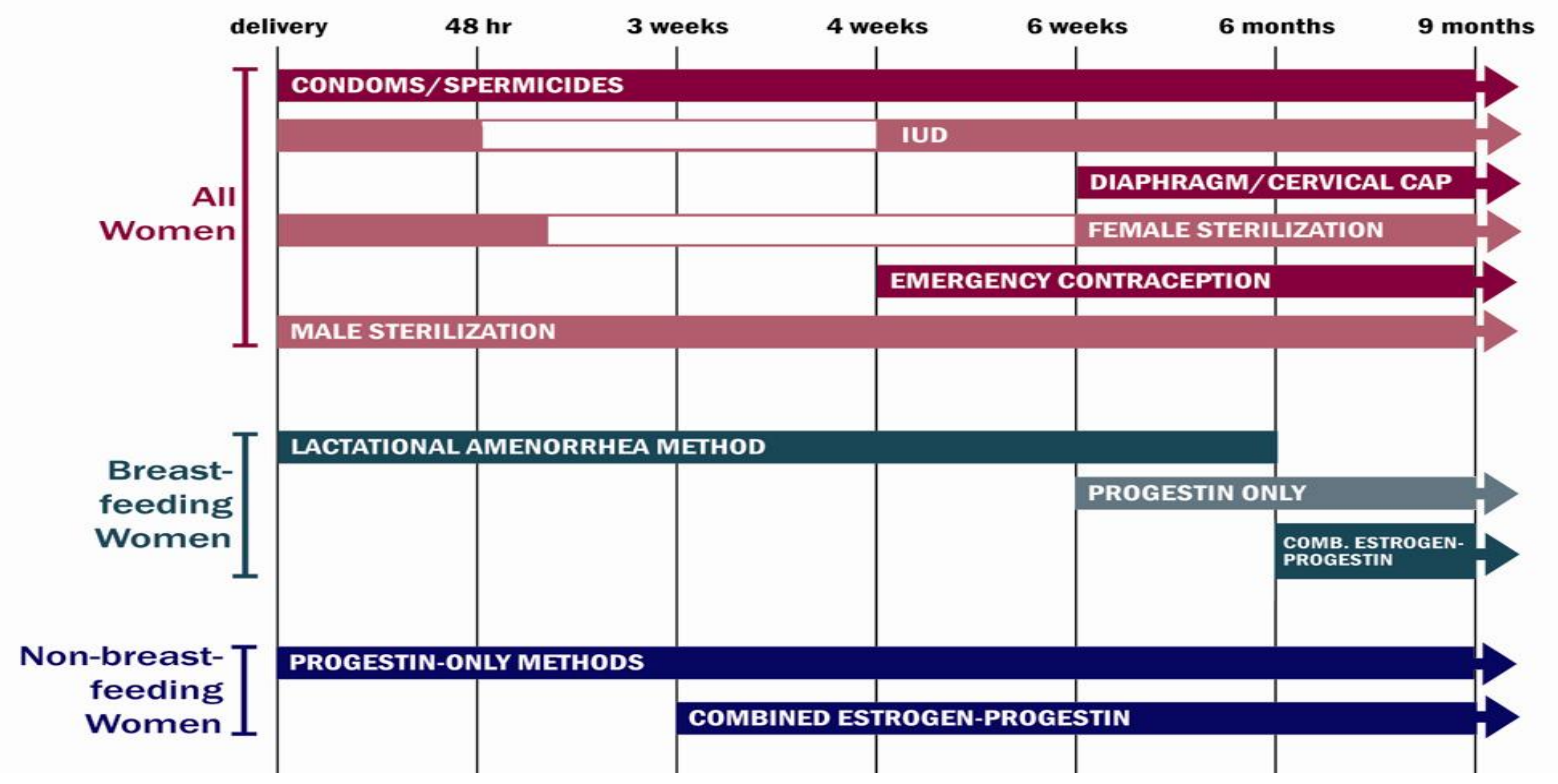

One of the targets in Kenya's second National Health Sector Strategic Plan (NHSSP) is to reduce the level of unmet need by increasing the contraceptive prevalence rate to $45 \%$ by 2007 and to $60 \%$ by 2010 . However there are no specific targets for increasing FP use among postpartum women 12 months after giving birth.

The HIV epidemic in Kenya has led to a rapid roll out of Prevention of Mother to Child Transmission (PMTCT) services, with a focus on reaching pregnant women during their antenatal visits. Postpartum care for new HIV+ mothers remains weak and is focused primarily on caring for their infant, with little attention being paid to the mother's health or to risky behaviors following delivery. Coordinating and integrating FP services with maternal and infant health services during and after pregnancy is feasible, as observed in the 'PMTCT Plus' approach (Myer et al 2005). However, even where women receive counseling on FP in PMTCT programs, use of contraceptives and condoms is low (AIDS and Behaviour 2008). 


\section{PROBLEM STATEMENT AND SOLUTION}

The postnatal period is neglected throughout Africa, as many women and their infants are not encouraged to seek care until six weeks after delivery, at which time they may or may not receive adequate attention. In addition, the FP needs of women during the first year postpartum are not well addressed in Kenya, with 68 percent of women having an unmet need by 12 months. Pregnant and postpartum women need information and services, provided at appropriate times, to address this unmet need, including those mothers who are HIV-positive. Providing a continuity of care from antenatal services, including PMTCT, delivery, and postpartum care, can ensure that women's health and fertility intentions are more likely to be effectively met. Health providers in Kenya have traditionally focused on providing postpartum care and FP for the first time at the sixth week; only nine percent of postpartum women who gave birth at home received a postnatal care visit within two weeks of delivery (KDHS 2003). There is clearly a need for providing information about the postnatal period not only during pregnancy, but also information and services at several points in time in the extended period postpartum.

To strengthen postnatal services, the Kenyan $\mathrm{MOH}$ has recently increased the number of visits recommended in the postnatal period to include a check up within 48 hours, and visits within two weeks and six weeks. This is outlined in the DRH Safe Motherhood and Neonatal Health Program (MOH/DRH 2005 - draft), but the feasibility and acceptability of providing postnatal care at these times has not yet been evaluated.

In order to develop and test this model of strengthened postnatal services, the Population Council's FRONTIERS project and Jhpiego's ACCESS-FP project (both funded by USAID) formed a partnership to support the DRH to introduce the model on a pilot basis and evaluate its feasibility and effectiveness. This strengthened model increased the number, timing and content of postnatal consultations that a woman and her newborn are expected and encouraged to receive. Following a collaborative process by all three partners in designing the intervention and the evaluation process, ACCESS-FP supported introduction of the intervention and provided technical support to the MOH for implementation, and FRONTIERS conducted the research and evaluation.

This intervention emphasized FP as a key component of the postnatal consultations. The content of each visit would be specific to the timing of the visit, such that it would be 'focused' postnatal care. The content of this series of visits would include: STI screening; maternal health checks; counseling on self care (breast care, clean perineum, maternal nutrition); vitamin A supplementation; newborn checks and counseling on basic newborn care (exclusive breastfeeding, clean cord care, warmth, infant feeding, hygiene, infant growth monitoring and immunization); danger signs for mother and newborn in postnatal period; FP information and services or referral; HIV testing (if status not known); nutritional and other supportive advice for HIV positive women; and ART for HIV positive women and babies; as well follow-up consultations if required. This intervention would be evaluated in terms of its feasibility, acceptability and effect on the quantity and quality of services received, and on women's postnatal reproductive health behaviors, including family planning. 


\section{STUDY OBJECTIVES}

1. To develop and introduce a strengthened postnatal care package with four consultations (within 48 hours and at two weeks, six weeks and six months) in one hospital and three health centers.

2. To document the feasibility and quality of care of the strengthened postnatal care package and its acceptability to providers and clients.

3. To evaluate the effectiveness of the postnatal package on women's reproductive health behavior, and on their and their infant's health status.

\section{DESIGN AND IMPLEMENTATION OF THE STRENGTHENED POSTPARTUM SERVICES PACKAGE}

Key intervention activities commenced in October 2006 and included: 1) a series of meetings with the $\mathrm{MOH}$ at central, provincial and district levels to sensitize stakeholders to the project, and ensure their commitment and participation in the package design; 2) development and pretesting an orientation training package; 3 ) training service providers in the strengthened services; and 4) conducting supportive supervision visits to follow up on trainees and address gaps identified.

1. Advocacy, sensitization and design meetings: $\mathrm{The} \mathrm{MOH}$ played a critical role in the design and implementation of the intervention. Several meetings of all three partners, led by the national DRH, were held at the start of the project, and with the Eastern Provincial Health Management Team (PHMT) and the Embu District Health Management Team (DHMT). A joint work plan was developed with the $\mathrm{MOH}$ and consensus reached on the timing and content of each consultation as well as the study sites.

2. Design of the four-visit postnatal package of services: The number and timing of visits at 48 hours, two weeks and six weeks were based on the existing DRH safe motherhood program recommendations in Kenya. To advise women using LAM about the need to transition to another method of contraception, the DRH agreed to pilot-test adding a fourth visit between four to six months to the package. A summary of the content of each of the four visits is given in Table 1 below.

A draft package of training materials on postnatal care (including postpartum family planning) was developed and then reviewed and revised by eight provincial and district staff from the MOH and staff from ACCESS-FP and FRONTIERS. The package of materials included guidance on the technical content of each visit as well as a contraceptive technology update oriented towards the family planning needs of postpartum women. The package was then pre-tested among 25 providers in the pilot $\mathrm{MOH}$ clinics in Embu district and changes made accordingly. The pre-test involved training a group of providers in the new training package over three days and assessing it in term of content, flow, duration and relevance. 
A three-day training package was designed with the objectives to:

$\checkmark$ Increase providers' knowledge and practice of postnatal care;

$\checkmark$ Increase counseling on the benefits of birth spacing to postnatal patients;

$\checkmark$ Increase providers knowledge on return to fertility;

$\checkmark$ Increase providers counseling on LAM and transition to other modern methods;

$\checkmark$ Increase counseling on other FP methods that are compatible with breast feeding;

$\checkmark$ Increase linking postpartum FP with other MCH consultations, such as immunizations, sick child visits or well baby checks.

Table 1: $\quad$ Timing and content of the PNC-FP package of care

\begin{tabular}{|c|c|c|}
\hline $\begin{array}{l}\text { Timing of } \\
\text { Assessment } \\
\text { or Visit }\end{array}$ & Services for the Mother & Services for the Baby \\
\hline $\begin{array}{l}\text { Assessment 1: } \\
\text { Pre-discharge } \\
\text { (or within } 48 \\
\text { hours if } \\
\text { delivered at } \\
\text { home) }\end{array}$ & $\begin{array}{l}\text { Focused physical exam } \\
\text { Counseling on early breastfeeding (EBF) and LAM } \\
\text { Healthy Timing and Spacing of Pregnancies FP } \\
\text { Maternal danger signs and management of complications } \\
\text { HIV \& syphilis tests as indicated } \\
\text { Refer to Comprehensive Care Centers (CCC) for HIV } \\
\text { follow up as indicated } \\
\text { Appointment for next visit }\end{array}$ & $\begin{array}{l}\text { EBF } \\
\text { Essential newborn care } \\
\text { Newborn physical exam } \\
\text { Newborn danger signs and } \\
\text { management of } \\
\text { complications } \\
\text { Nevirapine as indicated } \\
\text { Appointment for next visit }\end{array}$ \\
\hline $\begin{array}{l}\text { Assessment 2: } \\
\text { Two weeks at } \\
\text { MCH clinic }\end{array}$ & $\begin{array}{l}\text { Physical check } \\
\text { Maternal danger signs and management of complications } \\
\text { EBF counseling } \\
\text { Healthy Timing and Spacing of Pregnancy (HTSP } \\
\text { messages) } \\
\text { Return to sexual activity } \\
\text { Return to fertility } \\
\text { LAM and FP counseling and services } \\
\text { Appointment for next visit }\end{array}$ & $\begin{array}{l}\text { Essential baby care } \\
\text { Baby danger signs and } \\
\text { management of } \\
\text { complications } \\
\text { Immunization } \\
\text { EBF } \\
\text { Physical exam } \\
\text { Appointment for next visit }\end{array}$ \\
\hline $\begin{array}{l}\text { Assessment 3: } \\
\text { Six weeks at } \\
\text { MCH clinic }\end{array}$ & $\begin{array}{l}\text { Focused physical exam } \\
\text { Maternal danger signs and management of complications } \\
\text { LAM users- supportive counseling including transition } \\
\text { HTSP messages } \\
\text { Return to fertility and sexual activity } \\
\text { FP counseling and services (refer women for methods not } \\
\text { available at Health Centers) } \\
\text { Dual method use } \\
\text { Return visit }\end{array}$ & $\begin{array}{l}\text { Essential baby care } \\
\text { Danger signs and } \\
\text { management of illnesses } \\
\text { Immunization } \\
\text { Physical exam } \\
\text { EBF } \\
\text { Cotrimoxazole at } 4 \text { week } \\
\text { as indicated } \\
\text { Appointment for next visit }\end{array}$ \\
\hline $\begin{array}{l}\text { Assessment 4: } \\
\text { Four to six } \\
\text { months check- } \\
\text { up at } \mathrm{MCH} \\
\text { clinic }\end{array}$ & $\begin{array}{l}\text { Focused physical exam } \\
\text { Transition counseling for LAM users } \\
\text { HTSP messages } \\
\text { FP counseling and services (refer women for methods not } \\
\text { available at Health Centers) } \\
\text { Referrals for CCC as indicated }\end{array}$ & $\begin{array}{l}\text { Immunization as indicated } \\
\text { Physical exam } \\
\text { Support weaning and } \\
\text { continued breastfeeding } \\
\text { Vitamin A supplement } \\
\text { Return visit for well baby } \\
\text { and immunization at } 9 \\
\text { months }\end{array}$ \\
\hline
\end{tabular}


The final version of the PNC-FP orientation package is composed of three main parts:

\section{Introduction}

- Overview of care/objectives of training

- Major causes of maternal mortality

- Major causes of infant and neonatal mortality

- Effect of focused antenatal care on postnatal period

- Eight pillars of safe motherhood

- Overview of four focused postnatal assessments.

\section{Postnatal assessments/visits}

- Description of the four focused assessments:
○ 48 hours
- 1-2 weeks
○ 6 weeks
○ 4-6 months

- Components of each postnatal assessment:
- Maternal and newborn danger signs in postnatal period
- Management of postnatal complications
- PMTCT follow up for HIV positive women
- Immunization
$\bigcirc$ Infant feeding.

\section{Postpartum family planning}

- Postpartum considerations for family planning (see job aid in annex)

- Contraceptive technology updates reflecting current Kenyan MOH FP Guidelines.

- Supportive job aides provided to trainees:

- Summary of the WHO Medical Eligibility Criteria

- Postpartum FP methods compatible with breastfeeding and the appropriate timing to introduce contraceptive methods, with emphasis on LAM as the foundation of Postpartum FP (see adjacent figure).

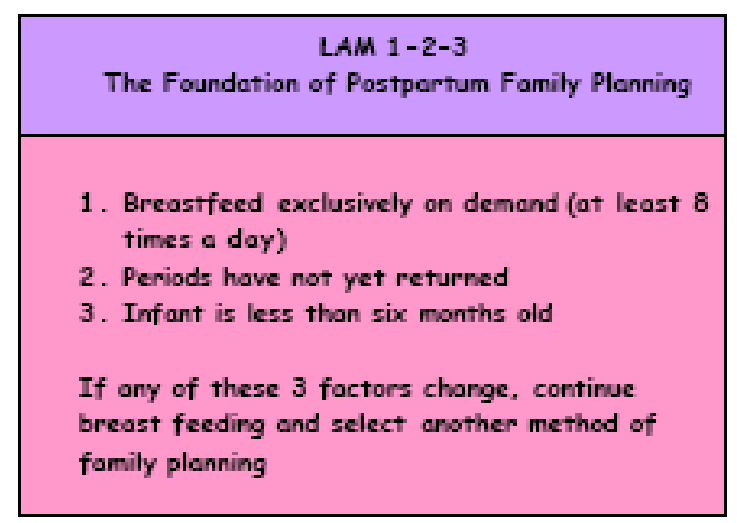

Participants worked in groups, discussed various case studies and were able to practice and demonstrate adequate skills in counseling for PPFP contraceptive methods in the classroom setting; this was enhanced by role playing. All participants developed individual action plans detailing how they were going to implement the strengthened package in their health facilities. This included orienting their colleagues who were unable to attend the training. The action plans formed the basis for discussions with all facility staff during the supportive supervisory visits. 


\section{Training providers in providing the package:}

Participants for the 3-day training were selected by the $\mathrm{MOH}$ using selection criteria developed jointly during a planning and advocacy meeting held in Embu town (see appendix). A schedule developed for the PNC orientation package guided the training (see appendix). Following pretesting of the orientation package in October 2006, the first threeday workshop was conducted in Embu Town in November 2006 for 22 health providers from the four sites. The participants included staff from the MCH/FP clinics including staff from ANC- PMTCT, maternity unit: postnatal ward, labor/delivery ward, and health centre incharges. Nine participants were from the PGH maternity unit, four from Karurumo and Kianjokoma Health Centers, three from Kibugi Health Center and five staff from provincial and district management teams (RH Coordinator, District Public Health Officer, District RH Coordinator, Provincial Trainer and VSC - Service Provider).

Unfortunately, in January 2007 all the providers in Embu PGH who had attended this training were transferred, which necessitated training a new team of providers in the PGH maternity and $\mathrm{MCH}$ clinic prior to the recruitment of the post-intervention group. In addition, it was noted that the majority of postpartum women giving birth in the hospital did not necessarily live near the hospital or the pilot health centres and therefore would not be able to receive any improved care following discharge from the PGH maternity unit. Consequently, two further training sessions were carried out in April 2007. In addition to 18 new providers from Embu PGH, a further 23 health providers were trained from the remaining 19 health facilities in the district, including one private health facility and two participants from Embu Medical Training College (ten of these participants had not received any updates in reproductive health for over fifteen years). During the immediate pre-post evaluation of the training sessions, the knowledge scores varied widely but showed improvements overall from pretest training scores of 35 percent -75 percent to posttest training scores of 50 percent -90 percent (see appendix for questionnaire used for evaluation).

4. Supportive Supervision: Supportive supervision is one of the most critical elements in any training process. Two supportive supervision visits were undertaken (in January and May 2007) by trainers from the MOH (Provincial RH coordinator and District RH coordinator) and staff from ACCESS-FP and FRONTIERS to observe practices, support providers and collect service data to monitor implementation. The visits were used to assess knowledge, application of that knowledge and skills learned, and to resolve gaps identified during the visit. Supervisors were trained on supervision and assessment of standards. A tool was developed to facilitate the supervision in conjunction with the DHMT. The District RH Coordinator participated in all the supportive supervision activities and her skills were developed to be able to conduct supportive supervision in the future.

5. Introduction of postpartum registers: Postpartum registers were initially developed by the $\mathrm{MOH}$ in 2005. They were subsequently reviewed and amended at the same time as all other $\mathrm{MCH} / \mathrm{FP}$ registers. The DRH agreed to pilot the newly updated postpartum register in Embu District. The first one-day training for the introduction of the registers took place in December 2006 for 13 providers. These providers were then asked to start using the register in the three postnatal wards and at the MCH at PGH Embu. At the end of the session feedback was given to the DRH on the feasibility of using the register. Subsequently, all 23 
sites in which staff had been trained received support and orientation on how to use the new registers. The information collected in the registers included: timing of the visit; counseling topics covered; number of infants receiving immunizations; clients counseled and tested; and clients referred for other follow-up.

In summary, implementation of the intervention to strengthen the package of postpartum services included:

$\checkmark$ A Postnatal Care - FP training package and job aides developed;

$\checkmark 73$ service providers from 23 out of 34 health facilities in Embu district oriented in the package;

$\checkmark$ All participants oriented in the new postpartum register and all 23 facilities started using it;

$\checkmark$ Supportive supervision visits carried out to assess knowledge and skills application;

$\checkmark$ Evaluations conducted after the trainings indicated that training objectives were achieved and expectations met.

\section{Factors affecting implementation of the package}

Contraceptive commodities supply: Supply of contraceptive commodities was sometimes erratic during the implementation period; for example, implants were only available for a short period. This may have affected FP use as some women may not have been able to obtain their method of choice (although implants are not commonly used among postpartum women).

Shortage of infection prevention commodities: Commodities such as chlorine solution, infection prevention buckets and appropriate personal protective equipment such as heavy duty gloves and aprons were not consistently available in the health facilities, which may have limited contraceptive method choice.

Referrals for postnatal services: Clear referral systems and follow-up were lacking, making it difficult to track clients through service statistics. The main reasons for referral were for long acting or permanent methods as dispensary staff were unable to provide permanent methods of contraception. If health providers have been trained in the MOH's RH/FP 8-week course they can provide the IUD and implants, but generally only pills, condoms and injectables are available at the dispensaries.

Weak linkages of maternal health care with child immunization services: The service statistics indicate that the number of infants who received $1^{\text {st }}$ Pentavalent and $1^{\text {st }}$ oral polio at 6 weeks does not correspond with the number of mothers assessed during the postnatal consultation at 6 weeks, although these two numbers would be expected to match. Monitoring data indicate that only about 50 percent of mothers of infants receiving immunizations were seen at the PNC clinic; one possible reason is that some infants are brought by other family members for their immunizations.

Baseline skills in management of maternal and newborn complications were very low: In developing the PNC-FP package, it was assumed that providers already had basic skills and so clinical training was not included in the package; assessments at baseline indicate that this was generally not the case. 
Facilities with limited numbers of FP providers trained in FP: Each of the pilot sites had at least one qualified FP health provider who was formally trained in the MOH eight-week RH/FP course. All other staff were trained on the job or attended the training within the intervention. For long acting and permanent methods to be more widely available, more providers need to be formally trained so that women do not have to travel to higher level facilities.

Staff rotation: The constant changeover of staff between departments and within units at the PGH adversely affected the provision of new services and record keeping.

\section{EVALUATION DESIGN AND METHODOLOGY}

\section{Key variables and indicators for objectives two and three}

\section{To document the feasibility and quality of care of the strengthened postnatal care package and its acceptability to providers and clients}

\section{Feasibility of implementation}

a. Facility readiness to offer the comprehensive focused postnatal package, (infrastructure, equipment, supplies, medicines registers, forms, IEC materials, and staff availability).

b. Provider knowledge and skills improved

c. Provider capacity to identify postnatal complications strengthened

\section{Acceptability to providers}

a. Providers indicating approval and satisfaction with offering comprehensive PNC package

b. Proportion of providers expressing confidence in their ability to provide PNC

c. Number of clients given dates to return for PNC

\section{Acceptability to clients}

a. Proportion of PP women who can recall the essential information on postnatal care that they received during ANC

b. Proportion of PP women who attend three postnatal consultations

c. Proportion of women who would recommend the postnatal services to others

\section{Quality of care}

a. Proportion of women who receive full package of care visits

To evaluate the effectiveness of the feasible postnatal package on women's reproductive health behavior, and on their and their infant's health status.

a. Proportion of all women who accept uptake of single contraceptive method by 6 weeks

b. Proportion of women using LAM during first 6 months

c. Proportion of infants receiving immunizations increased

d. Continued use of any FP method after 6 months

e. Method switching rates at 6 months.

f. Mean duration of contraceptive use. 


\section{Study Sites}

The study sites were selected jointly by all three partners. The study was implemented in Embu District, Eastern Province, to the east of Mount Kenya approximately two hours north east of Nairobi where Jhpiego had already been working closely with the MOH to strengthen ANC services as well as supporting implementation efforts through the USAID-funded APHIA II program. The intervention was implemented in the $\mathrm{MCH}$ and maternity units in the Provincial General Hospital (PGH) and in three health centers - Karurumo Rural Health Training Center, Kianjokoma Health Center and Kibugu Health Center - that are used as clinical training sites for both in-service and pre-service nursing trainees.

The facilities selected fulfilled the following criteria:

1. Providers have been trained in and offer focused antenatal care;

2. PMTCT services are available, including counseling and testing and ARV (based in the ANC clinic);

3. Counseling and support for safe infant feeding available

4. FP counseling and referral available

5. Functioning laboratory on-site.

The PGH in Embu town has the highest level of deliveries for any facility in the district and so was selected to ensure a large number of women available for recruitment into the study at the time of delivery. Although the three health centers do offer delivery services, to ensure consistency in exposure to the service received, only women attending Embu PGH for delivery were recruited for the evaluation.

\section{Study designs}

Two related designs were used to address the second and third study objectives:

1. A pre - post intervention facility assessment was used to collect information from the facilities to document the feasibility and acceptability of the new model, and to assess any changes in provider knowledge and competence, and in the quality of postnatal care received following introduction of the strengthened model;

2. A pre - post intervention longitudinal cohort study design was used to measure and compare the reproductive health behaviors of comparable groups of postpartum women before and after introduction of the strengthened postpartum care package.

Each design required different data collection methods to measure the key variables described above. Similar tools were used for collecting data before and after introducing the intervention. Data collectors were newly qualified midwives and social scientists who were trained for five days, including role playing to internalize the data collection instruments. Supervisors checked all completed instruments for data quality and accuracy prior to data entry and analysis. Data were entered using Epi Info and converted to SPSS for analysis. Pearson's Chi square tests were used to determine the significance of differences between the pre- and post-intervention results. A p-value of less than 0.05 was used as the threshold for significance. 


\section{Facility Assessment}

Documenting feasibility and acceptability of the intervention: Indicators for measuring facility readiness to offer the strengthened services were measured before the intervention was introduced in all four facilities through a facility inventory of the resources necessary and available, e.g. infrastructure, equipment, commodities, test kits, stationary client cards and notes, ARV drugs and other medications required to provide the services as well as staffing. The intervention did not involve strengthening the infrastructure, equipment or increasing the staffing of the clinics and therefore these items were not measured after the intervention.

Following the introduction of the new model, a "settling-in" period of four months was allowed for the new activities to become integrated as routine procedures, after which their feasibility and acceptability were measured. Where available, service statistics were reviewed before and after the intervention to describe utilization of antenatal care, post delivery, family planning, postnatal care and PMTCT services. These were collected over the equivalent six-month periods (January - June 2006 and January - June 2007).

Assessing provider competence and quality of care: These indicators were measured using the following methods, once before the intervention was introduced in all four clinics, and again at 4-5 months afterwards:

1. In depth interviews with providers to determine their knowledge and skills for postpartum and newborn care, including FP, their understanding of the organizational set up of postnatal services including perceived barriers and for encouraging early postnatal visits, and their attitudes towards the changes in policy and procedures. Mean scores were computed from the provider knowledge questionnaire to give a composite score for knowledge.

All providers working in the antenatal, family planning, child welfare and postnatal clinics in the $\mathrm{MCH}$ unit in the hospital and health centers, and those working in the maternity postnatal ward at the hospital were approached for an interview before and after the intervention. A total of 40 service providers ( 22 from the health centers and 18 from PGH) were interviewed pre- intervention, and 45 interviewed afterwards ( 20 from the health centers and 25 from PGH). It is important to note, however, that these were not necessarily the same providers due to attrition and transfer of providers over this time period especially at PGH; 36 of the providers interviewed post intervention had participated in the training ( 80 percent).

Almost all of the health providers were female and nurses or nurse midwives (Table 3). The number of years worked at the facilities ranged from one year to 27 years. Around a third of the nurses pre and post intervention had worked in the facility since 2000, just under half started work in the facility between 1990 and 1999 and the remainder started before 1990. Half of the providers had formal FP training. 
Table 2: Types of health providers interviewed, pre and post intervention

\begin{tabular}{|c|c|c|c|c|}
\hline \multirow[t]{2}{*}{ Cadre of provider: } & \multicolumn{2}{|c|}{ Health Center staff } & \multicolumn{2}{|c|}{ Hospital staff } \\
\hline & Pre & Post & Pre & Post \\
\hline Enrolled nurses or nurse/midwives & 18 & 16 & 11 & 12 \\
\hline Registered nurse or nurse/midwives & 3 & 3 & 7 & 13 \\
\hline Clinical Officer & 1 & 1 & 0 & 0 \\
\hline Total & 22 & 20 & 18 & 25 \\
\hline
\end{tabular}

2. Direct observation of client-provider interactions were used to measure provider competence and their ability to follow service provider guidelines for care. Using a standardized checklist, qualified nurse-midwives were trained to observe and record the quality of care provided at four points in time: within 48 hours; within two weeks; within six weeks; within six months. Prior to introducing the intervention, health providers did not routinely provide postnatal services within 48 hours or within two weeks in the MCH clinic, or at six months, and so quality of care could only be measured post-intervention for services provided at these times. Consequently before and after comparisons were only possible for the six week service. All observations were carried out during the same time period with cross-sectional samples of women for each category. All women attending for these services during the data collection period were approached and requested for permission to observe their consultation. Table 3 describes the sample sizes achieved.

\section{Table 3: Numbers of client-provider interactions observed}

\begin{tabular}{l|cccc}
\hline \multirow{2}{*}{ Observations } & \multicolumn{2}{|l}{ Pre-intervention } & \multicolumn{2}{c}{ Post- intervention } \\
\cline { 2 - 5 } Client - provider interaction within 48 hours & PGH & HC & PGH & HC \\
Client - provider interaction within 2 weeks & - & - & 29 & $\dagger$ \\
Client - provider interaction within 6 weeks & 49 & 37 & 30 & 40 \\
Client - provider interaction within 6 months & - & - & 26 & 42 \\
\hline$-\quad$ No data available as these consultations were not carried out prior to intervention \\
$+\quad$ Very few deliveries took place in the health centers
\end{tabular}

Mean scores were computed for groups of indicators of quality of care and these were then aggregated to give composite scores for quality of care given. This method was used to demonstrate overall improvements in care and knowledge rather than individual aspects.

\section{Longitudinal cohorts}

Pre and post intervention cohorts of postpartum women were recruited on the postnatal ward in Embu PGH and compared to evaluate the effectiveness of the intervention on women's RH behaviors postpartum. Women were interviewed to measure the following indicators: fertility intentions; preferred timing of starting FP; use of FP; knowledge of danger signs; and completed immunizations. The pre-intervention cohort was recruited before the new care package was introduced and the post-intervention cohort recruited after the four-month settling-in period. 
These women were interviewed on the postnatal ward within 48 hours of delivery before they left the ward. Women in the post intervention cohort were interviewed after the comprehensive first postnatal check within 48 hours, although in Kenya women often leave facilities within 12 24 hours of giving birth. Women were eligible for inclusion if they gave their informed consent to be interviewed at three different times: immediately (i.e. pre-discharge); at six months; and at 12 months $^{3}$. Women were excluded if they experienced complications during childbirth that resulted in obvious pain or were heavily medicated; women who had a still birth or a sick baby in the newborn unit were also excluded.

For the pre-intervention cohort, all women delivering at PGH during September - October 2006 were recruited until the required sample size (see below) was reached. When following-up the pre-intervention group at six months, however, it became apparent that many of them lived outside the province (Embu Town borders Central and Eastern Provinces) and were difficult to find, resulting in a larger than anticipated lost to follow-up rate. Consequently, for the postintervention group, women were eligible for inclusion only if they lived within Embu District. Women who agreed to participate in all three interviews were informed that a researcher would contact them for the second and third interviews six and 12 months later. At the time of recruitment, the woman's name, physical address, and a phone number (where available) were recorded. For the second and third interviews, the women were offered the option of the researcher visiting their homes or of meeting at a mutually agreeable neutral location (including at the hospital). They were also informed that their travel costs would be reimbursed if interviewed away from their homes. Using a structured Kiswahili or English written consent form (depending on their preferred language), all women were informed about the objectives, procedures, benefits, and risks of the study. Informed consent was obtained individually for each interview. Because of time constraints for completing the project, it was only possible to interview the post-intervention cohort at six months postpartum. The pre-intervention cohort was interviewed at both six and 12 months.

The key variable of interest for calculating the cohort sample size was the proportion of women using a family planning method at 12 months following birth. The pre-intervention proportion was not available for Embu District, and so the contraceptive prevalence rate (CPR) for Eastern Province from the KDHS in 2003 was used (50.6\% for any method and 38.4\% for any modern method among married women). To calculate the sample size required to compare contraceptive prevalence of the pre- and post- intervention groups at 12 months and to demonstrate a programmatically valuable effect, it was hypothesized that the intervention would lead to an increase of at least 15 percentage points in the CPR in the post-intervention group compared with the pre-intervention group. To detect a 15 percentage point difference with a power of $80 \%$, the minimum sample size for each cohort would be 169 . To allow for a $30 \%$ loss to follow up, a sample size of 242 would be needed for each cohort. As can be seen in Table 5, the minimum sample sizes for both cohorts were exceeded at recruitment and six months. A larger than anticipated lost-to-follow-up occurred for the pre-intervention group between recruitment and six months, but the sample size achieved (173) is still larger than that calculated to be sufficient to make comparisons between the groups (169).

3 The study design originally anticipated following the cohorts for 12 months, but lack of time and funding meant that the period had to be reduced to six months. 
Table 4: Sample sizes for the longitudinal cohorts of postpartum women

\begin{tabular}{l|ccc}
\hline & $\mathbf{4 8}$ hours & $\mathbf{6}$ months & $\mathbf{1 2}$ months \\
\hline Pre-intervention cohort & 273 & 173 & 155 \\
Post-intervention cohort & 250 & 221 & - \\
\hline
\end{tabular}

Social scientists were trained in interviewing the postpartum women. To assist in tracing the women after six months, the district MOH assigned six Public Health Technicians (PHT) to work with the researchers. PHTs are issued with motorbikes to carry out their work in the community and were therefore able to carry the researchers around the communities (all wore safety helmets). Their knowledge of the local area and the availability of their motorbikes proved invaluable in finding the women's homes, as there is very limited public transport once off the main tarmac roads and the topography is very hilly.

Cohort characteristics: As can be seen in Table 5, the pre-intervention and post-intervention cohorts were statistically equivalent for all socio-demographic and reproductive health characteristics. Despite slight differences in the age distribution, the mean age of women in both cohorts was very similar (26 years vs. 25.5 years) and there were similar distributions of levels of schooling. A little over half of the women in both cohorts had previously used family planning and had similar parity. Significant differences were found, however, in the proportions of women and their partners testing for HIV, which probably reflect the rapid increases nationwide of HIV testing in ANC due to the rollout of the PMTCT program.

Table 5: Characteristics of postpartum cohorts interviewed within $\mathbf{4 8}$ hours of delivery

\begin{tabular}{|c|c|c|c|c|}
\hline \multirow{2}{*}{ Indicators } & \multicolumn{2}{|c|}{ Pre-intervention } & \multicolumn{2}{|c|}{ Post-intervention } \\
\hline & $\%$ & $\mathbf{N}$ & $\%$ & $\mathbf{N}$ \\
\hline Age $15-19$ years & $17 \%$ & 169 & $10 \% *$ & 221 \\
\hline Age $20-24$ years & $30 \%$ & 169 & $43 \%$ ** & 221 \\
\hline Age 25-29 years & $26 \%$ & 169 & $23 \%$ & 221 \\
\hline Age $30-34$ years & $17 \%$ & 169 & $18 \%$ & 221 \\
\hline Median age of postpartum women & 25 years & 169 & 24 years & 221 \\
\hline Primary or lower education & $61 \%$ & 171 & $53 \%$ & 219 \\
\hline Secondary education & $31 \%$ & 171 & $40 \%$ & 219 \\
\hline Completed high school or above & $8 \%$ & 171 & $6 \%$ & 219 \\
\hline Attended ANC clinic & $96 \%$ & 171 & $99 \%$ & 221 \\
\hline Ever had HIV test & $90 \%$ & 169 & $98 \%$ ** & 221 \\
\hline Tested in ANC & $85 \%$ & 159 & $95 \%$ ** & 216 \\
\hline Client shared results & $88 \%$ & 153 & $86 \%$ & 216 \\
\hline Client HIV Negative & $89 \%$ & 161 & $94 \%$ & 216 \\
\hline Client HIV Positive & $3 \%$ & 161 & $6 \%$ & 216 \\
\hline Partner tested & $34 \%$ & 169 & $49 \%$ ** & 221 \\
\hline Partner shared results & $34 \%$ & 164 & $96 \%$ ** & 109 \\
\hline Child ever died & $11 \%$ & 171 & $10 \%$ & 221 \\
\hline Partner wants same number of children & $72 \%$ & 160 & $68 \%$ & 221 \\
\hline Ever used /avoided getting pregnant in past & $54 \%$ & 170 & $54 \%$ & 220 \\
\hline Parity & 2.3 & 170 & 2.1 & 221 \\
\hline
\end{tabular}




\section{STUDY LIMITATIONS}

Although the health facilities are typical of those found across Kenya, this study had some limitations. The study was facility-based and all women interviewed delivered in a facility, which represents about only about $42 \%$ of women giving birth in Kenya. These women tend to be better educated and have higher income and so may not be representative of all postpartum women in the country. The contraceptive prevalence rate in Eastern Province is around 51 percent (with use of modern methods at 38\%), which is higher than the national rate of 39 percent (KDHS 2003). Just over half of both groups of women (54\%) had ever used anything or tried in any way to delay or avoid getting pregnant in the past. Compared with the provincial CPR average of $51 \%$ (which also includes districts with very low CPRs), this suggests that women in Embu district are probably more highly motivated to use contraception than the average.

The client-provider observations of PNC-FP services for 48 hours were only recorded at the PGH for the post-intervention group. Observations of services for the two-week, six-week and six month visits included clients that did not deliver at either the hospital or one of the study health centers and so they may have different needs or characteristics to women who delivered at the hospital.

Because of time constraints when undertaking the study, the pre-intervention group was recruited only three months prior to the provider training. This suggests that there might have been be some contamination because the pre-intervention group may have received the improved care at their six week and/or six month consultations. However, analysis of the data indicates that only 30 women in the pre-intervention cohort used the four intervention health facilities and so may have been exposed to the improved services. A sensitivity analysis was undertaken to address this possibility by including and excluding these 30 women from analyses and no significant differences were found.

\section{FINDINGS}

\section{Feasibility of implementation}

\section{Facility readiness}

An index of facility readiness to provide the PNC-FP package was constructed using six composite indicators measured through data collected from the facility inventory:

1. Availability of services (score range: 0-13): including weighing the client, taking blood pressure, health education sessions, counseling for HIV, birth preparedness and family planning, blood tests (anemia, syphilis and HIV), urine testing, vaccinations (TT), PMTCT and STI treatment.

2. Availability of essential equipment (score range: 0-10): including BP machine, stethoscope, foetoscope, scales, (adult and infant), tape measure, thermometer, speculum, examination couch and spotlights.

3. Availability of essential drugs (score range: 0-11): including the expected range of micronutrient supplements, antibiotics, (such as cotrimoxazole, gentamicin and amoxicillin 
in tablet, injection and syrup forms) and ARVs tablets and syrups (nevirapine, AZT, ZDV, Combivir).

4. Availability of essential vaccines (score range: 0-6): including BCG, Polio, DPT, HBV, measles and tetanus toxoid.

5. Availability of essential family planning commodities (score range: $0-9$ ): including injectables, COC, POP, IUD, male/ female condoms, implants, female and male sterilization (permanent methods of contraception are not provided at health centre level).

6. Availability of in-service staff trainings within past year (score range 0-12): including updates in different aspects of PMTCT, HIV counseling and support to comprehensive antenatal care, screening and STIs, management of labor, newborn care (low birth weight, sick newborn), infant feeding, FP and postnatal care.

Table 6 summarizes each of the composite indicators of readiness prior to the intervention. The reasonably high scores indicate that all four facilities had the basic capacity to provide the improved package of care.

Table 6: Summary of health facilities' preparedness at baseline

\begin{tabular}{lccc}
\hline & $\begin{array}{c}\text { PGH and HCs } \\
\text { average score } \\
(\mathbf{n = 4})\end{array}$ & $\begin{array}{c}\text { PGH only } \\
\text { average score } \\
(\mathbf{n}=\mathbf{1})\end{array}$ & $\begin{array}{c}\text { HCs only } \\
\text { average score } \\
(\mathbf{n}=\mathbf{3})\end{array}$ \\
\hline $\begin{array}{l}\text { Availability of } \\
\text { Services offered (0-13) }\end{array}$ & 10.5 & & \\
Equipment available (0-10) & 9 & 8 & 11.3 \\
Essential drugs (0-11) & 7.3 & 7 & 9.3 \\
Essential vaccines (0-6) & 6 & 6 & 7.3 \\
Family planning commodities (0-9) & 7 & 8 & 6 \\
In-service staff training in past (0-9) & 8 & 7 & 6.7 \\
Total score (0-58) & $\mathbf{4 7 . 8}$ & $\mathbf{4 4}$ & 8.3 \\
\hline
\end{tabular}

Although all in-charges at the health facilities stated that they required more staff, there were adequate numbers of registered and enrolled nurse/midwives working in the maternity and $\mathrm{MCH}$ units. Prior to the intervention a total of 62 nurses worked in the maternity unit and 11 nurses in the PGH MCH; 9 nurses worked in Kibugu HC, 10 nurses in Karurumo HC and 10 nurses in Kianjokoma HC.

\section{Provider knowledge of maternal and newborn health services}

After the intervention, more nurses reported having ever received training in postnatal care, increasing from 35 percent to 80 percent. Provider knowledge of maternal and newborn complications in the postnatal period was measured using a scale aggregating scores from indicators of the main causes of maternal and neonatal morbidity and mortality. The scores were generated from the provider knowledge questionnaire and an average score computed for each component. 
The PNC-FP orientation package touched only briefly on complications in the postnatal period. The two commonest complications in the postnatal period for the mother are postpartum hemorrhage (PPH) and sepsis. There were limited and non-significant improvements in providers' knowledge on signs of PPH (from a mean score of 2.1 to 2.3 out of 4), which included un-contracted uterus (75\% vs. $71 \%$ ), signs of shock (58\% vs. 58\%), amount of external bleeding (25\% vs. $31 \%)$ and retained placenta (50\% vs. $71 \%)$.

However knowledge of essential actions for managing PPH showed significant improvement, from a mean score of 1.9 to 2.6 out of four. These included massaging the fundus (33\% to 58\%), emptying the woman's bladder (20\% to $51 \%$ ) giving IV oxytocin (65\% to $71 \%)$, and starting IV fluids $(68 \%$ to $82 \%)$. Table 7 indicates that knowledge on all signs of puerperal sepsis improved (although none of them significantly) after the training, with the composite score increasing from 1.88 to 2.53 out of a possible 5 .

Table 7: Proportion of providers able to state signs for detecting sepsis in the mother during the postnatal period

\begin{tabular}{l|cc}
\hline \multicolumn{1}{c|}{ Indicator } & $\begin{array}{c}\text { Pre } \\
\text { intervention } \\
(\boldsymbol{n = 4 0 )}\end{array}$ & $\begin{array}{c}\text { Post } \\
\text { intervention } \\
(\boldsymbol{n}=\mathbf{4 5})\end{array}$ \\
\hline Signs of sepsis: & & \\
High pulse & $28 \%$ & $38 \%$ \\
High fever & $63 \%$ & $67 \%$ \\
Septic shock (un-recordable BP) & $43 \%$ & $64 \%$ \\
Foul smelling lochia & $35 \%$ & $49 \%$ \\
Tender abdomen & $20 \%$ & $36 \%$ \\
\hline
\end{tabular}

Figure 2 shows (non-significant) improvements in management of sepsis, with a mean score increasing from 1.3 to 1.6 out of 3 ; clearly there is a need for further improvements in this area.

Figure 2: Provide knowledge on management of sepsis

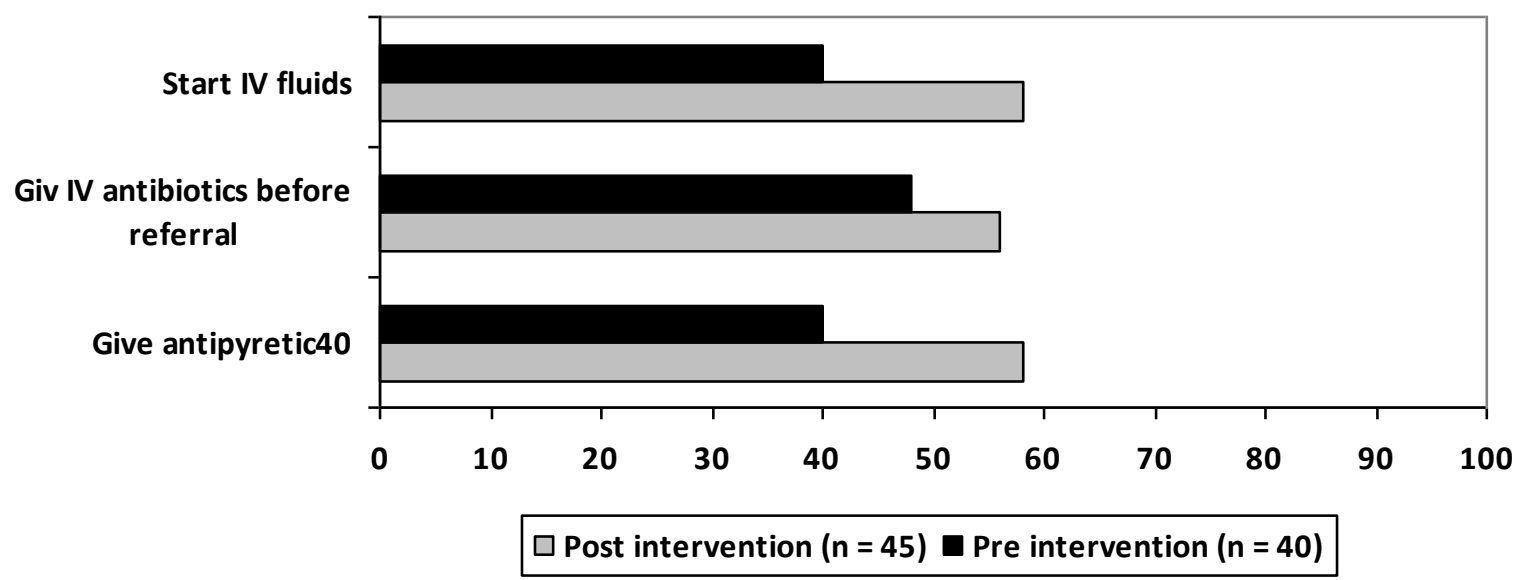


Nevertheless, there were significant improvements in provider knowledge of counseling and support for care of the infant after birth before discharge from the hospital; for example, in observing proper feeding before discharge (28\% vs. $80 \%$, ) and proper attachment and positioning of the breastfeeding baby ( $22 \%$ vs. $51 \%)$. The proportion of providers who remembered signs of newborn infection increased for difficulty in feeding (63\% vs. 82\%) and difficulty breathing (18\% vs. 53\%), but decreased for knowledge of high or low temperature (70\% vs. 62\%). Providers' knowledge also improved on actions they would take for managing newborn infection: temperature (33\% vs. 60\%), keeping baby warm (35\% vs. $47 \%$ ) and start antibiotics (78\% vs. $84 \%)$.

Table 8 describes the summary scores for knowledge of newborn care, indicating a nonsignificant increase overall. There were non-significant increases in knowledge of management of low birth weight infants: ensure thermal protection ( $88 \%$ vs. $71 \%)$, support mother to establish breastfeeding (73\% vs. $84 \%$ ) and ensure infection prevention (38\% vs. 53\%) Although level of knowledge increased slightly after the training, it remains at about half of what is expected (6.4 out of 10) and so enhanced training on clinical-based training for complications may be warranted.

Table 8: Provider knowledge of signs and actions to manage newborn complications

\begin{tabular}{l|cc}
\hline \multirow{2}{*}{\multicolumn{1}{c|}{ Indicator }} & $\begin{array}{c}\text { Pre-intervention } \\
(\boldsymbol{n}=\mathbf{4 0 )}\end{array}$ & $\begin{array}{c}\text { Post-intervention } \\
(\boldsymbol{n}=\mathbf{4 5})\end{array}$ \\
\cline { 2 - 3 } & Average score & Average score \\
Signs of newborn infection $(0-3)^{\star *}$ & 1.5 & 1.98 \\
Action for newborn infection $(0-4)$ & 1.73 & 2.33 \\
Care of low birth weight baby $(0-3)$ & 1.98 & 2.09 \\
Total: newborn complications $(\mathbf{0}-\mathbf{1 0})$ & $\mathbf{5 . 2}$ & $\mathbf{6 . 4 0}$ \\
\hline
\end{tabular}

$* \mathrm{p}<0.05 * * \mathrm{p}<0.01$

Provider recall of the key maternal and newborn health messages for counseling women during the first week postpartum stayed relatively high (averaging 64 percent), but there were few statistically significant changes after the training, apart from the danger signs in mother and baby increased significantly from 15 percent to 40 percent $(\mathrm{p}<0.01)$. For example, awareness of the need to provide FP counseling increased from 73 to 80 percent, personal hygiene increased from 70 to 84 percent, infant feeding from 60 to 76 percent, baby care from 73 to 84 percent, counseling on maternal nutrition from 58 to 73 percent, care of breasts from 60 to 67 percent.

\section{Provider knowledge of family planning}

Providers were asked to describe which FP methods they would normally offer to breastfeeding women within 48 hours, at two weeks and at six weeks after childbirth. As table 9 shows, there was a remarkable increase in providers indicating that they would offer women any FP method at the 48 hours and two week consultations (multiple methods could be mentioned, so the totals are greater than $100 \%$ ). Before the intervention, over half the providers said they would not offer any method at 48 hours or two weeks, and those that did would discuss only LAM or condoms. 
After the intervention, the vast majority of providers said they would recommend LAM and many would discuss the IUD and female sterilization.

Before the intervention, six weeks had clearly been seen as the most appropriate time to start discussing FP; this intervention has greatly increased the range of methods that providers know they should discuss with women at this consultation.

Table 9: Proportion of providers' reporting offering FP methods to breastfeeding women during postpartum consultations

\begin{tabular}{|c|c|c|c|c|c|c|}
\hline & \multicolumn{2}{|c|}{48 hours } & \multicolumn{2}{|c|}{2 weeks } & \multicolumn{2}{|c|}{6 weeks } \\
\hline & $\begin{array}{c}\text { Pre } \\
(n=40)\end{array}$ & $\begin{array}{l}\text { Post } \\
(n=45)\end{array}$ & $\begin{array}{c}\text { Pre } \\
(n=40)\end{array}$ & $\begin{array}{l}\text { Post } \\
(n=45)\end{array}$ & $\begin{array}{c}\text { Pre } \\
(n=40)\end{array}$ & $\begin{array}{c}\text { Post } \\
(n=45)\end{array}$ \\
\hline & $\%$ & $\%$ & $\%$ & $\%$ & $\%$ & $\%$ \\
\hline Any method & 45 & $96^{* *}$ & 45 & $96^{* *}$ & 97 & 100 \\
\hline LAM & 25 & $91^{* *}$ & 28 & $84^{* *}$ & 20 & $52^{* *}$ \\
\hline IUCD & 5 & $69^{* *}$ & 0 & $20^{* *}$ & 55 & $88^{* *}$ \\
\hline Female sterilization & 3 & $29^{* *}$ & 0 & $32^{* *}$ & 13 & $56^{* *}$ \\
\hline Hormonal implants & 3 & 2 & 0 & $28^{* *}$ & 48 & $80^{* *}$ \\
\hline Condom & 13 & $33^{* *}$ & 10 & 28 & 28 & $64^{* *}$ \\
\hline Injectables & 3 & 9 & 0 & $24^{* *}$ & 58 & $88^{* *}$ \\
\hline Combined pill & 0 & 4 & 0 & $20^{* *}$ & 3 & $36^{* *}$ \\
\hline Progestin only pill & 0 & 9 & 3 & $36^{* *}$ & 75 & 80 \\
\hline Vasectomy & 0 & 4 & 0 & 12 & 5 & $24^{*}$ \\
\hline Emergency contraception & 0 & 0 & 0 & 8 & 8 & 12 \\
\hline
\end{tabular}

*p $<0.05 * * \mathrm{p}<0.01$

\section{Quality of care}

Client-provider interactions were observed to assess the quality of care provided after the intervention on the postnatal ward at Embu PGH at 48 hours $(\mathrm{n}=29)$ and in the three MCH-FP clinics at two weeks $(n=64)$, six weeks $(n=70)$ and six months $(n=68)$. The 48 hour, two week and six month consultations were not routine prior to the intervention and so none were observed pre-intervention; six week consultations were routine and so were also observed before the intervention $(n=86)$. The full range of maternal and newborn health services, including family planning, which are components of the new PNC-FP package, were assessed through these structured observations and mean scores computed for each indicator and then aggregated across all indicators to give composite scores.

\section{Essential maternal care}

Asking about danger signs since childbirth: (bleeding since birth, color/smell of vaginal discharge, condition of perineum/CS scar, fever, headache or blurred vision, swelling in face, hands or feet, signs of thrombophlebitis, tiredness or breathlessness, convulsions or fits). At the six weeks consultation, only four major signs are expected to be screened (bleeding, vaginal discharge condition of perineum/CS scar and fever). 
In all consultations providers are expected to ask postpartum women if they have experienced any of these problems since birth, and should also counsel women on potential symptoms of complications. As table 10 shows, for the majority of consultations within 48 hours of delivery, women were asked about any bleeding since birth, the color and smell of their lochia, although few asked about the condition of the perineum or signs of thrombosis. At 48 hours the mean composite score was 2.24 out of four.

\section{Table 10: Proportions of observed consultations after the intervention in which women were asked about maternal danger signs}

\begin{tabular}{l|ccc}
\hline \multirow{2}{*}{ Indicator } & 48 hours & $\mathbf{2}$ weeks & $\mathbf{6}$ weeks \\
\cline { 2 - 4 } & $\mathbf{( n = 2 9 )}$ & $\mathbf{( n = 6 4 )}$ & $\mathbf{( n = 7 0 )}$ \\
$\%$ & 76 & 61 & 39 \\
Heavy bleeding since birth & 76 & 72 & 41 \\
Color/smell of vaginal discharge since birth & 93 & 36 & 21 \\
Condition of perineum & 24 & 13 & - \\
Signs of thrombosis & 14 & & \\
\hline
\end{tabular}

At the two week consultation, fewer providers inquired about the danger signs since childbirth, with a mean composite score of 2.02. By six weeks, although a woman's body has normally returned to its pre-pregnancy state, providers were less likely to ask about key danger signs even though bleeding and infection are two postnatal complications that are relevant up to six weeks. Some women may experience infected perineum and may not volunteer this information to the provider unless specifically asked. Given the life-threatening nature of hemorrhage and sepsis, screening for danger signs as part of postnatal care requires further improvement as the mean composite score at six weeks was 1.11 out of 4 .

Counseling about danger signs: Most providers were observed counseling or giving messages to the mother at 48 hours on the possible danger signs: excessive bleeding (89\%), foul smelling vaginal discharge (93\%) and broken episiotomy scar (56\%).

Physical examination conducted within 48 hours and two weeks: (observe general appearance, temperature, pulse, BP, check for pallor, examine breast and nipples and palpate abdomen for uterine involution). During consultations observed on the postnatal ward, all women had their blood pressure taken, four-fifths their temperature taken, but only one-third had their pulse measured. All postpartum women were palpated for uterine involution and virtually all $(97 \%)$ were given a general examination and had their breasts examined.

During the two-week consultations in the MCH clinics, the most frequent actions carried out were to observe general appearance (92\%), take BP (83\%) and examine breasts and nipples and palpate abdomen (75\%). In 67 percent of the two week consultations, providers checked the women's eyelids and palms for pallor (signs of anemia). The total mean composite score at 48 hours was 5.48 out of 7 , and at two-weeks was 4.59 out of 7 . 
Tests conducted: At the 48 hour consultation, all women were observed being asked whether they had received HIV and $\mathrm{Hb}$ tests during their pregnancy.

Counseling for HIV/STIs: (discussed STI symptoms/signs, effects of HIV/STI in postpartum period, presence of STI/HIV symptoms, discussed STI/HIV risk factors, inquired about STI/HIV risk factors, and discussed how to prevent STI/HIV, use of condom, and partner CT for HIV). In less than one fifth of consultations on the postnatal ward were risk factors, prevention of STIs/HIV and condom use discussed, although providers did discuss the importance of partners counseling and testing for HIV with 79 percent of women. There were no increases at the twoweek consultations, but some improvements from the pre-intervention period were observed at the post-intervention six week consultations in discussing STI/HIV risk factors (7\% to 18\%) and how to prevent STI/HIV (7\% to $24 \%$ ); the proportion of consultations where partner counseling and testing was discussed doubled from 13 to 26 percent. In very few of the six month consultations, however, were any discussions on STI/HIV observed.

Quality of care at the six-week visit: Comparisons of the quality of care provided at six weeks were possible between the pre- and post-intervention groups (see table 11). Overall, the total score for the quality of care provided tripled. Significant improvements were observed in individual actions such as screening for: bleeding since birth (15\% to 39\%); color/smell of vaginal discharge (17\% to $41 \%$ ); condition of episiotomy ( $0 \%$ to $20 \%$ ); and fever (1\% to $20 \%$ ). There were also significant improvements $(\mathrm{p}<0.01)$ for examinations at six weeks, specifically in recording vital signs: temperature taken (7\% vs. $49 \%)$, pulse taken (1\% vs. $32 \%)$ and BP taken (34\% vs. $75 \%$ ). Examination of breast and nipples and abdomen for uterine involution increased significantly $(\mathrm{p}<0.05)$ from $35 \%$ to $52 \%$. These dramatic improvements in all aspects of quality of care are highly encouraging, but given the poor level of care found during the pre-intervention assessments the composite score after the intervention (8.72 out of 25) still falls short of the level desired (see table 11).

Table 11: Summary of quality of care indices for maternal health at six weeks

\begin{tabular}{|c|c|c|}
\hline \multirow{2}{*}{ Composite indicators } & $\begin{array}{c}\text { Pre-intervention } \\
(n=86)\end{array}$ & $\begin{array}{c}\text { Post-intervention } \\
(n=70)\end{array}$ \\
\hline & Average score & Average score \\
\hline Asking about danger signs since childbirth $(0-4)^{* *}$ & 0.47 & 1.56 \\
\hline Physical examination conducted $(0-7)^{\star *}$ & 1.88 & 3.79 \\
\hline Tests conducted $(0-2)^{\star *}$ & 0.01 & 0.52 \\
\hline Family planning $(0-4)^{* *}$ & 0.53 & 1.7 \\
\hline Counseling on HIV/STIs* $(0-8)$ & 0.51 & 1.15 \\
\hline Total score $(0-25)^{\star \star}$ & 3.4 & 8.72 \\
\hline
\end{tabular}

$* \mathrm{p}<0.05 * * \mathrm{p}<0.01$

Note: family planning indices are discussed in detail in the section 'return to family planning'.

\section{Essential newborn care}

Asking about danger signs since birth: during the 48-hour consultations providers were observed asking mothers if their newborns had difficulty breathing (38\%) or feeding (79\%), such 
as poor sucking or not sucking and if the baby felt too hot or too cold (62\%). The mean composite score was 1.79 out of 3 . At the two-week consultation, around half of the providers asked about the three dangers signs, with an overall composite score of 1.47 out 3 .

Counseling on danger signs specific to the early postnatal period: the key danger signs are difficulty breathing, difficulty feeding, and baby has fever/ too cold. During the consultations within 48 hours, the danger signs mothers were most frequently counseled on were: redness around umbilical stump (97\%) and feeding difficulties, temperature control, and jaundice (all at $62 \%$ ). The mean composite score for quality of counseling at 48 hours was 1.69 out of 3 . Temperature control (58\%), feeding difficulties $(56 \%)$ redness around umbilicus $(52 \%)$ and breathing difficulty $(41 \%)$ were the most frequently mentioned danger signs by providers in the two-week consultations. Comparisons between the pre- and post-intervention groups at the six week consultation showed significant increases after the intervention for counseling on difficulty with feeding (12\% to 50\%), difficulty with breathing (5\% to 39\%), and whether the baby felt hot or cold $(8 \%$ to $50 \%)$. Once again, while providers' performance was significantly improved by the training, the overall quality of care provided started and remains weak.

Immunizations received: (Polio, $\mathrm{BCG}$, and Pentavalent). During all consultations on the postnatal ward, newborns were observed receiving polio 0 vaccine and BCG. In the observed two-week provider-client interactions, babies were observed receiving BCG in 38 percent of consultations and receiving Polio 0 vaccine in 36 percent of consultations. These were mothers who had not delivered in a facility and were making their first visit following childbirth. After the intervention, providers at the six week consultation were much more likely to administer immunizations: polio 1 vaccine (68 percent vs. 94 percent) and HBV/DPT/Pentavalent (58 percent vs. 88 percent).

Infant feeding counseling: (advice on infant feeding, encourage mother to discuss management of breastfeeding and re-emphasize exclusive breast feeding). In all consultations within 48 hours, providers gave advice to mothers on infant feeding and most of the time $(82 \%)$ encouraged a discussion on how they were managing the feeding. Women were more likely to get this service at the 48 hour consultation than at subsequent consultations, but advice and emphasis on breastfeeding remained high across the time period (see table 12). A sizable proportion of providers were observed requesting women to demonstrate breastfeeding: 59 percent within 48 hours, 50 percent within two weeks and to 46 percent at six weeks. The mean composite score for counseling on infant feeding was highest within 48 hours at 2.76 out of 3 .

\section{Table 12: Proportion of consultations in which postpartum women were observed receiving counseling on infant feeding}

\begin{tabular}{l|ccc}
\hline \multirow{2}{*}{\multicolumn{1}{c|}{ Indicator }} & $\mathbf{4 8}$ hrs & 2 weeks & $\mathbf{6}$ weeks \\
\cline { 2 - 4 } & $\mathbf{( n = 2 9 )}$ & $\mathbf{( n = 6 4 )}$ & $\mathbf{( n = 7 0 )}$ \\
& $\%$ & $\%$ & $\%$ \\
Advice on infant feeding & 100 & 97 & 97 \\
Re-emphasize exclusive breastfeeding & 100 & 92 & 75 \\
Encourage mother to discuss management & 82 & 56 & 56 \\
\hline
\end{tabular}


More of the post-intervention cohort of women (58\%) said that they had received information about infant feeding during pregnancy than before the intervention (24\%); however, significantly fewer of the post-intervention cohort said they were breastfeeding on the ward (83\% vs. 96\%), and fewer women said they were able to breastfeed within one hour of birth (42\% vs. 20\%).

After the intervention, provision of infant feeding advice during the six-week consultation increased significantly, from 59 percent to 97 percent of consultations, and the proportion of consultations in which providers were observed requesting mothers to demonstrate feeding practices also increased significantly from 10 percent to 46 percent.

At six months postpartum, women were asked to recall if any providers had recommended anything about breastfeeding. Before the intervention, 48 percent mentioned that exclusive breastfeeding had been recommended; this increased significantly to 70 percent after the intervention and more women (29\%) after the intervention recalled providers encouraging them to breastfeed on demand than before (13\%), Very few women could remember whether providers discussed how exclusive breastfeeding benefits the mother ( $4 \%$ before and $11 \%$ after the intervention). Over 90 percent of women were still breastfeeding after six months, both before and after the intervention, but none exclusively.

Even though there was an almost doubling in the overall scores for the quality of infant health care observed during the provider - client interactions at six weeks (see table 13), especially in counseling on danger signs and infant feeding, the post-intervention scores remain lower than would be desired.

Table 13: Comparison of mean summary quality of care scores for infant health observed during the six weeks consultations

\begin{tabular}{l|cc}
\hline \multirow{2}{*}{ Summary Indices: } & Pre-intervention & Post-intervention \\
\cline { 2 - 3 } & $(\mathbf{n = 8 6})$ & $(\mathbf{n}=\mathbf{7 0})$ \\
Asking about any danger signs $(0-3)^{\star *}$ & Mean score & Mean score \\
Counseling on possible danger signs $(0-3)^{\star *}$ & 0.55 & 1.11 \\
Counseling on infant feeding $(0-3)^{\star *}$ & 0.24 & 1.39 \\
Immunizations received $(0-2)^{\star *}$ & 1.33 & 2.19 \\
Total quality of care index for newborn $(\mathbf{0}-\mathbf{1 1})^{\star *}$ & 1.25 & 1.76 \\
\hline
\end{tabular}

$* * \mathrm{p}<0.01$

\section{Return to fertility and family planning}

Table 14 describes the quality of counseling on fertility and family planning observed after the intervention on the ward and in the PNC clinic. Among those women counseled on FP, two or more methods were discussed in 76 percent of the 48 hour consultations and in 67 percent of the two week and six week consultations. At the six week consultation, 81 percent of clients received their preferred method. The mean composite scores for the quality of FP counseling 
were highest during the 48 hour consultations, with a mean score of three out of a possible four items discussed, whereas at the six week consultation the mean score was 1.7 out of 4 .

Table 14: Proportion of women receiving counseling on FP and fertility post-intervention

\begin{tabular}{l|ccc}
\hline & \multicolumn{3}{c}{ Consultations } \\
\hline \multirow{2}{*}{ Indicators } & 48 Hrs & 2 Weeks & $\mathbf{6}$ Weeks \\
\cline { 2 - 4 } & $(\mathbf{n = 2 9 )}$ & $\mathbf{( n = 6 4 )}$ & $\mathbf{( n = 7 0 )}$ \\
& $\%$ & $\%$ & $\%$ \\
Return to fertility & 83 & 49 & 67 \\
Return to sexual activity & 69 & 50 & 45 \\
Advising on FP & 86 & 83 & 40 \\
Healthy timing and spacing of pregnancies & 86 & $\mathrm{n} / \mathrm{a}$ & 40 \\
\hline
\end{tabular}

(n/a) this information was not recorded

Figure 3 compares the quality of fertility and FP counseling during the six week consultations. The intervention led to dramatic improvements in all of the indicators, with over two thirds of women being advised about return to fertility and at least two methods, and over 80 percent of women being asked about and receiving their preferred method. Other important issues were discussed with only 30-40 percent of women, but this still represents significant increases from before the intervention was introduced.

Figure 3: Proportions of women counseled on return to fertility and family planning at 6 weeks, pre- and post- intervention

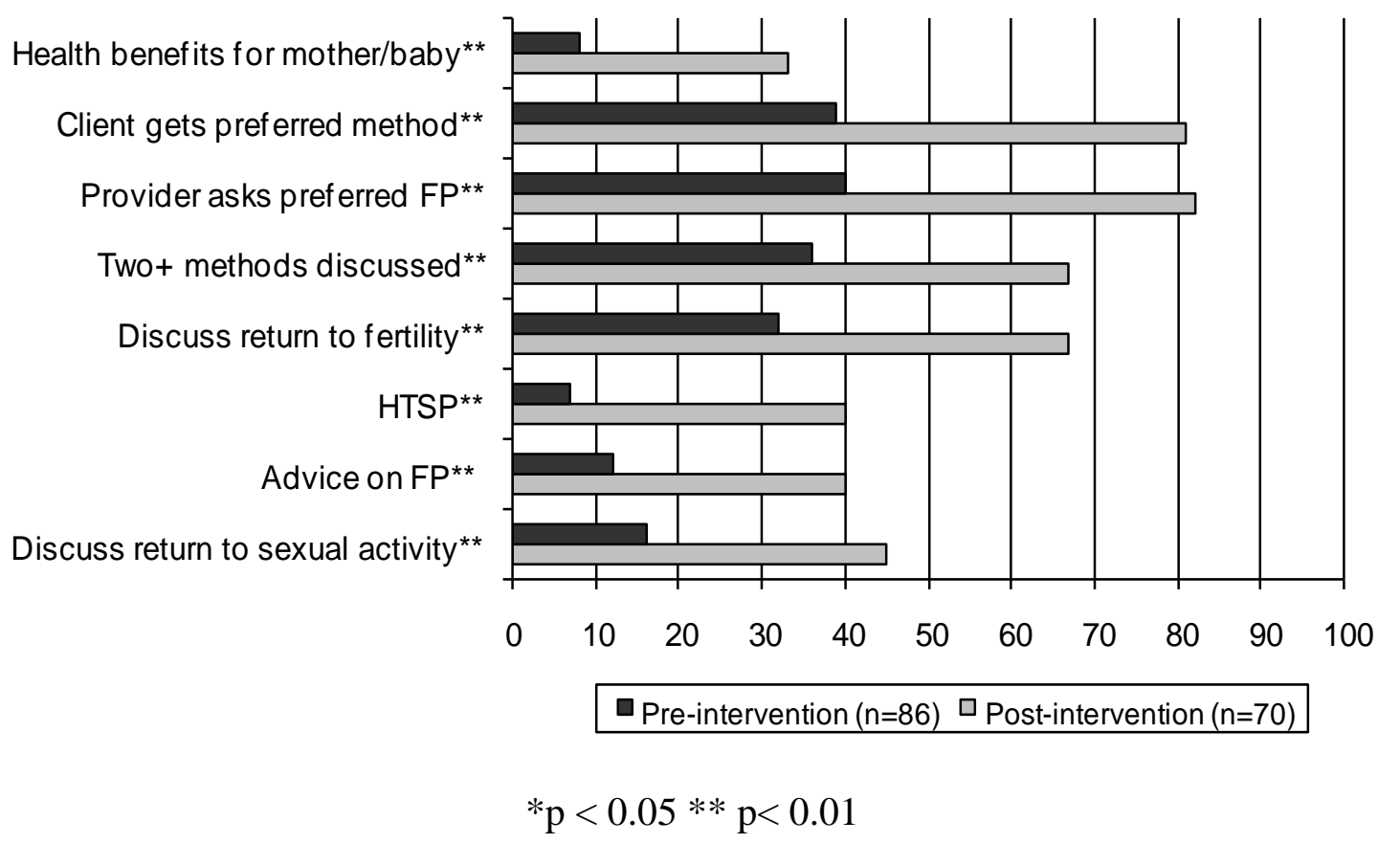


Table 15 describes the FP methods that postpartum women were observed deciding to use during the two week and six week consultations. The data were collected concurrently using the same observation checklist in the four health facilities and observing the same providers. After the intervention, the lower level of FP use during the six week visit than the two week visit (63\% vs. $84 \%$ ) is because many women attending the six week consultation had already received an FP method before leaving the health facility after birth or during the two week visit. It is highly encouraging to note that at the two weeks consultations, only 16 percent of the women were not using any form of family planning. Two thirds of those practicing FP at two weeks were using LAM, although very few (4\%) used a condom as well as LAM. Other methods being used at two weeks included implants (4\%), vasectomy (2\%), and condoms (4\%).

Table 15: FP methods chosen or started by women during consultations at 2 weeks and 6 weeks

\begin{tabular}{|c|c|c|c|}
\hline \multirow[b]{2}{*}{ Indicator } & \multirow{2}{*}{$\begin{array}{c}2 \text { Weeks } \\
\begin{array}{c}\text { Post-intervention } \\
(\mathrm{n}=60)\end{array}\end{array}$} & \multicolumn{2}{|c|}{6 Weeks } \\
\hline & & $\begin{array}{l}\text { Pre-intervention } \\
\qquad(\mathrm{n}=68)\end{array}$ & $\begin{array}{l}\text { Post-intervention } \\
(\mathrm{n}=62)\end{array}$ \\
\hline Any FP method chosen during consultation & $84 \%$ & $35 \%$ & $63 \%$ ** \\
\hline Among those using FP & $\begin{array}{c}(n=54) \\
\%\end{array}$ & $\begin{array}{c}(n=30) \\
\%\end{array}$ & $\begin{array}{c}(n=44) \\
\%\end{array}$ \\
\hline LAM only & 67 & 0 & $16^{*}$ \\
\hline Progestin only pill & 6 & 57 & $7^{* *}$ \\
\hline IUD & 6 & 3 & $30^{* *}$ \\
\hline Injectable & 9 & 30 & 30 \\
\hline
\end{tabular}

$* \mathrm{p}<0.05$ and $* * \mathrm{p}<0.01$ between pre and post intervention at 6 weeks only

Although significantly more women were using LAM at six weeks post intervention, this was not as high as might be expected - women appear to prefer a contraceptive method rather than a 'behavior' to prevent pregnancy. Another notable difference was the decrease in use of the progestin only pill and increase in use of the injectable and IUD. The high level of IUD uptake is attributable to the renewed focus and skills training on provision of and access to the IUD which had been targeted during the training for the six week consultation. Other methods chosen at the six week consultation included implants (7\%) and female sterilization, condoms, and SDM (two percent each).

\section{Rapport with clients}

A composite score was calculated for observations of client-provider rapport at 48 hours using nine indicators (provider greeted the client, ensured confidentiality, ensured privacy, asked the client how she was feeling, looked at client's health card during consultation, asked if there were any concerns, asked if client understood all information, courteous to client throughout, give client a return date). Out of a possible score of nine, the mean score was 8.97, indicating very high levels of rapport established by the providers with their postpartum clients. All women were counseled to return for the second postpartum consultation after two weeks at the clinic and an appointment was made. At the two week consultations, rapport scores remained high, with a 
mean score of 7.78. The weakest element was that in only 44 percent of consultations did providers try to ensure confidentiality. Significant improvements after the intervention were also noted during the six week consultations; ensuring privacy increased from 60 to 100 percent, confidentiality from 5 to 63 percent, and providers asking the client how she was feeling from 22 to 90 percent.

\section{Acceptability of postpartum services to providers}

Following the intervention providers were asked whether they were satisfied with the care they gave postpartum women. Just over half of the providers $(55 \%)$ at the health centers $(n=20)$ and 80 percent at Embu PGH $(n=25)$ were satisfied with the care they provided, although over 85 percent of health center staff and 50 percent of hospital staff felt there was room for improvement. The issues raised were a high work load, poor infrastructure (especially to ensure privacy), insufficient equipment, supplies and training materials, and the need for more training. Five of the hospital providers would like all services to be provided in the same building or room to better provide an integrated service.

Only one provider thought that the two week visit was unrealistic while others thought three visits would be adequate. Twenty out of 25 hospital providers thought that the mother and baby should attend for four postpartum visits. Half of the health center providers and 84 percent of hospital providers said they were confident that they could provide the strengthened postpartum care package. Others would like further updates or consolidation of information, mainly because it is a 'new' concept and some feel they forget some of the items because it is not yet fully ingrained into their work.

\section{Acceptability and use of postpartum services to clients}

There was a significant increase, albeit from 94 percent among the pre-intervention group to 98 percent of the post intervention group of women on the postnatal ward, who said they would recommend the service to others. Offering and encouraging postpartum visits clearly results in increased attendance: the mean number of postpartum consultations attended by women over the six month period increased from 2.06 visits to 2.53 visits per woman and an increase was also noted in the mean number of visits made by their infants, from 4.98 visits to 5.98 visits per infant.

\section{Fertility and family planning behaviors at six months}

The evaluation also sought to measure the extent to which the intervention might affect a number of fertility and family planning behaviors by comparing cohorts of women who had received the standard postpartum care (i.e. the pre-intervention group) with those that had received the improved care (i.e. the post-intervention group). Interviews were carried out on recruitment at 48 hours on the postnatal ward at Embu PGH and again six months later at a mutually acceptable location. The sample size, recruitment and follow-up of these two groups of women are described earlier. 


\section{Knowledge of return to fertility and child spacing}

The intervention did not have an effect on women's awareness of when they might be able to conceive following childbirth; this awareness remained very low at $15 \%$ in the pre-intervention group and $9 \%$ in the post-intervention group. However, when interviewed at 48 hours, notably more women after than before the intervention reported that child spacing had been discussed during ANC (35\% vs. 19\%), indicating that the intervention has been somewhat effective in increasing awareness of fertility-related issues - although only one third of women appear to have received FP messages during ANC.

Women on the postnatal ward were asked their preferred timing for a provider to discuss family planning with them. Women in the post-intervention group were significantly more likely to express a preference for discussing FP during ANC consultations (31\% vs. $8 \%$ ), which may reflect the fact that more of them received information at this time. As expected, very few are interested in information at the time of delivery ( $2 \%$ vs. $0 \%$ ), but counseling on the postnatal ward was acceptable for 24 percent for both groups of women. After the intervention, fewer women preferred to receive FP information at the six week check (40\% vs. $24 \%$ ). Women do not have any particular preferences therefore, and so FP information should be offered at any opportunity during ANC and PNC services.

As table 16 indicates, when interviewed at six months, women in the post-intervention group were significantly more likely to report having been counseled on various issues about FP by a provider at some time during the six month period, including being offered a method, either on the postnatal ward or subsequently. The only exception was a reduction in providers mentioning about STI/HIV prevention and FP methods.

Table 16: Proportion of women reporting FP issues discussed during consultations between childbirth and six months postpartum

\begin{tabular}{|c|c|c|}
\hline Indicator & $\begin{array}{c}\text { Pre- } \\
\text { intervention } \\
(n=173) \\
\% \\
\end{array}$ & $\begin{array}{c}\text { Post- } \\
\text { intervention } \\
(n=221) \\
\% \\
\end{array}$ \\
\hline Client recalled that providers discussed FP since delivery** & 70 & 90 \\
\hline Provider mentions a FP method that also protects against STIs/HIV* & 64 & 52 \\
\hline Provider mentions condoms as protection against STIs/HIV & 95 & 99 \\
\hline Provider offered FP method since delivery ${ }^{\star *}$ & 68 & 84 \\
\hline Client offered FP method after childbirth but before leaving hospital ** & 7 & 19 \\
\hline
\end{tabular}

$* * p<0.01$

After the intervention, significantly more women knew that if the three criteria of LAM were met then it constituted an FP method (18\% vs. 33\%), although at the six month interview very few women said they had used LAM specifically to prevent pregnancy (6\% vs. $5 \%)$. The main reason given for stopping using LAM was because the women had stopped breastfeeding exclusively and started another method (6 out of 9). Data from the client - provider interactions in the postnatal clinic (i.e. a different group of women) also showed a rapid decrease in use of LAM over the first two month period (see table 15 above). 
It is important to note that there were some significant differences in expressed fertility intentions between women in each group that may have subsequently influenced their postpartum behaviors. Women in the pre-intervention group were more likely than those in the post-intervention group to report that this had been a unplanned pregnancy (39\% vs. 30\%); these women were also more likely, however, to have mis-timed this pregnancy, i.e. it was wanted but at a later date (26\% vs. $13 \%)$. Indeed, 21 percent of women in the pre-intervention group reported that they would not be unhappy to become pregnant a few weeks after birth, compared with only nine percent of women in the post-intervention group.

Table 17 illustrates some differences in fertility intentions between the two groups at six months, with the post-intervention group significantly less likely to want to have more children and, for those wanting another child, to know when they wanted the next child. This may indicate that the counseling received within the intervention has helped women to realize the benefits of spacing pregnancies and to be more decisive about their fertility intentions.

Table 17: Proportion of women expressing fertility intentions at 6 months

\begin{tabular}{|c|c|c|}
\hline & $\begin{array}{c}\text { Pre-intervention } \\
\quad(n=171)\end{array}$ & $\begin{array}{c}\text { Post-intervention } \\
\quad(n=220)\end{array}$ \\
\hline Women who intend to have more children ${ }^{* *}$ & $91 \%$ & $69 \%$ \\
\hline Of those wanting another child: & $\begin{array}{c}(n=154) \\
\%\end{array}$ & $\begin{array}{c}(n=153) \\
\%\end{array}$ \\
\hline Intend to have another child within 2 years & 1 & 1 \\
\hline Intend to have another child in 2 to 3 years ${ }^{* *}$ & 3 & 15 \\
\hline Intend to have another child after 3 years & 66 & 67 \\
\hline Do not know when to have another child ${ }^{* *}$ & 31 & 18 \\
\hline
\end{tabular}

$* \mathrm{p}<0.05 \quad * * \mathrm{p}<0.01$

Most women interviewed on the postnatal ward within 48 hours said that they intended to use FP during the subsequent 12 months; significantly more women made this statement after than before the intervention ( $84 \%$ vs. 68\%). The majority of women in both groups were also in favor of starting to use a method at six weeks after childbirth, and a few women after the intervention said they intended to start using FP between six weeks and six months (2\% vs. $7 \%$ ).

By the six month interview, 74 percent of the pre-intervention group and 77 percent of the postintervention group reported using a FP method, suggesting that the intervention has not had an effect on overall use of FP by six months. Although there was no difference in overall use of FP between the two groups at six months this finding masks some important differences that seem to have occurred and that may be associated with the intervention.

First, there were significant differences in the timing of starting to use an FP method. As table 18 shows, before the intervention only six percent of women had started using FP by two months, whereas this had increased to $62 \%$ of women in the post-intervention group. 
Table 18: Timing of FP method uptake among women using FP at 6 months postpartum

\begin{tabular}{|c|c|c|}
\hline When mother started FP after delivery & $\begin{array}{c}\text { Pre-intervention } \\
(n=131) \\
\%\end{array}$ & $\begin{array}{c}\text { Post-intervention } \\
(n=175) \\
\%\end{array}$ \\
\hline In the first one month after birth of baby ${ }^{* *}$ & 0 & 6 \\
\hline One complete month but less than two** & 6 & 56 \\
\hline Two complete months but less than three ${ }^{\star \star}$ & 54 & 19 \\
\hline Three complete months but less than four ${ }^{\star \star}$ & 18 & 5 \\
\hline Between four and six months & 22 & 14 \\
\hline
\end{tabular}

Second, there were some differences in the type of method used at six months. Table 19 indicates that women in the post-intervention group were more likely to be using combined pills rather than progestin-only pills, and although still small, significantly more were using condoms. An encouraging although not significant trend is seen in more users of female sterilization ( $\mathrm{n}=3$ vs. $\mathrm{n}=8$ ). This method mix reflects the method mix for Kenya overall, however, with the majority choosing the injectable and very few users of long acting or permanent methods.

Table 19: Use of FP by method at six months postpartum

\begin{tabular}{|c|c|c|}
\hline FP method & $\begin{array}{c}\text { Pre-intervention } \\
(n=126) \\
\%\end{array}$ & $\begin{array}{c}\text { Post-intervention } \\
(n=166) \\
\%\end{array}$ \\
\hline Injectables & 60 & 55 \\
\hline Combined pill* & 11 & 18 \\
\hline Progestin only pill* & 17 & 6 \\
\hline Implants & 5 & 5.5 \\
\hline Female sterilization & 2 & 5.5 \\
\hline Condom (male or female) ${ }^{\star *}$ & 0 & 5 \\
\hline Natural methods & 2 & 3 \\
\hline IUD & 2 & 2 \\
\hline LAM & 1 & 0 \\
\hline Vasectomy & 0 & 0 \\
\hline
\end{tabular}

There were no significant differences in the proportion of women who had switched their FP method since delivery (17\% pre-intervention vs. $15 \%$ post-intervention). Of those who switched, six out 24 women in the pre-intervention group compared to 12 out of 28 in the post-intervention group did so because they had not got their preferred method initially. Five percent $(n=6)$ of women in the pre-intervention group stopped using FP within the six months period (after an average of 2.67 months) compared with nine percent $(\mathrm{n}=14)$ in the post-intervention group (who stopped after an average of 4.01 months); three women in both groups stopped and then restarted using an FP method. 
Although not a significant difference, 15 percent of pre-intervention and 19 percent of postintervention women said they did not receive their preferred method. Women were not asked why they did not receive their preferred method; however frequent stock outs of the more popular methods may have been the reason. This is in contrast with the six weeks consultations, during which less than 39 percent of the pre-intervention women received their method of choice compared to 81 percent of the post-intervention women. However, it is highly possible that some of the women may have used facilities that were not included in the four pilot facilities.

Thirdly, significantly more women in the pre-intervention group (80\%) than the postintervention group (66\%) reported that their menses had returned by 3 months postpartum, which suggests that the breastfeeding information given to the post-intervention group may be associated with more effective breastfeeding behavior.

Table 20: Summary characteristics of women concerning fertility and family planning at six months postpartum

\begin{tabular}{|c|c|c|}
\hline Indicator: & $\begin{array}{c}\text { Pre-intervention } \\
(n=170) \\
\% \\
\end{array}$ & $\begin{array}{c}\text { Post-intervention } \\
(n=220) \\
\%\end{array}$ \\
\hline Ever use of FP (reported at 48 hours) & 54 & 54 \\
\hline $\begin{array}{l}\text { Intended to use FP } 6 \text { weeks after delivery } \\
\text { (reported at } 48 \text { hours) }\end{array}$ & 56 & 57 \\
\hline Information at the 6 month interview: & $(n=142)$ & $(n=221)$ \\
\hline Currently using FP at 6 months & 74 & 77 \\
\hline Return to menses by 6 months & 64 & 65 \\
\hline Return to sexual activity by 2 months & 40 & 37 \\
\hline Return to sexual activity by six months & 78 & 80 \\
\hline Resumed sexual activity and using FP method & 64 & 71 \\
\hline Resumed sexual activity and not using FP method & 14 & 9 \\
\hline Pregnant $^{* *}$ & 3 & 0 \\
\hline Plans to have another child after 3 years* & 61 & 46 \\
\hline Does not plan to have any further children ${ }^{\star *}$ & 9 & 31 \\
\hline
\end{tabular}

Fourthly, although not a statistically significant difference, a much smaller proportion of women post-intervention (9\%) than pre-intervention (14\%) had an unmet need for family planning at six months, in that they were sexually active but not using contraception (see Table 20). Table 20 also demonstrates that more women who had resumed sexual activity were using contraception in the post-intervention group (71\%) compared to the pre-intervention group (64\%).

Fifthly, among the pre-intervention group, six women (3\%) had become pregnant by the six months interview, whereas no women in the post-intervention group were pregnant at six months. As noted above, dramatic improvements were observed in the quality of counseling on fertility and FP at the 6 week consultation, which may be associated with this improvement in fertility regulating behaviors; after the intervention, women were much more likely to have received repeated postpartum messages on exclusive breastfeeding, LAM, the benefits of healthy pregnancy spacing, return to fertility and contraceptive methods compatible with breastfeeding. 
Of these six women, two said their babies had died shortly after birth and so wanted to get pregnant again. Both these women were 19/20 years old with only primary school education. The remaining four women who were pregnant had a live six month old infant and three of them had not attended for any postnatal checkup. The other was a woman over 35 years, with no schooling and had four children. She had started using FP (injectable) but stopped 'because she wanted to'.

Sixthly, nine women $(6 \%)$ in the pre-intervention group and one woman in the post-intervention reported at six months that their babies had died, either at birth or shortly afterwards. Seven of the nine babies died on the ward (three of the women had a cesarean section and their babies went straight to the newborn unit). The other two babies died at two weeks and six weeks and had not been taken for any PNC assessments. Only one of the women who lost their baby in the pre-intervention group attended PNC before six weeks because she felt unwell. Five did not attend PNC at all. The woman in the post intervention group who lost her baby did attend PNC three times, the first being within 7 to 14 days.

Table 21 indicates that, after the intervention, significantly more women and their infants attended postnatal clinics earlier and more frequently in the six months following childbirth, and significantly more women had completed the $3{ }^{\text {rd }}$ Pentavalent vaccination for their infants $(98 \%$ vs. 90\%). These changes may be important factors contributing to this substantial reduction in the number of infants dying in each cohort.

\section{Table 21: Proportion of women and infants making visits to health facilities during six months following childbirth}

\begin{tabular}{|c|c|c|}
\hline Visits made to health facility during 6 months & $\begin{array}{c}\text { Pre-intervention } \\
(n=107) \\
\% \\
\end{array}$ & $\begin{array}{c}\text { Post-intervention } \\
(n=175) \\
\% \\
\end{array}$ \\
\hline Mother made first visit within 14 days $^{* *}$ & 2 & 28 \\
\hline Infant made first visit within 14 days ${ }^{* *}$ & 2 & 30 \\
\hline Mother made second visit $6-8$ weeks ${ }^{*}$ & 8 & 24 \\
\hline Infant made second visit $6-8$ weeks ${ }^{\star *}$ & 7 & 22 \\
\hline Average number of visits made by mother in 6 months ${ }^{* *}$ & 2.06 & 2.53 \\
\hline Average number of visits made by infant in 6 months ${ }^{\star *}$ & 4.98 & 5.98 \\
\hline
\end{tabular}

$* * \mathrm{p}<0.01$

\section{DISCUSSION}

This study sought to develop and introduce a strengthened postnatal care package that included postpartum family planning and four focused consultations: within 48 hours, within two weeks, at six weeks and at six months. The study documented the feasibility, acceptability and quality of the improved care package and evaluated its effectiveness on women's reproductive and infant health behaviors.

A PNC-FP orientation package was developed. This package expanded the existing content of PNC to incorporate comprehensive care for both mother and baby, and strengthened the continuum of care from ANC through 6 months postpartum. The package incorporated essential 
maternal and newborn care in the first days after childbirth and at the same time provided opportunities to inform and provide appropriate family planning advice and methods (according to the breastfeeding status and time postpartum) at several points in time.

Provider capability to provide the range of services required for providing this targeted PNC-FP package was developed through a three-day orientation training together with supportive supervision in the immediate months following the training. Providers reported being both satisfied and confident with the care they give postpartum women. Their complaints mainly concerned system and infrastructure issues that were beyond the scope of the package itself. Data from the health facility assessments, however, indicated that each facility was sufficiently prepared prior to the intervention to provide PNC.

The training proved effective in increasing the knowledge and performance of most providers in the key component services of the PNC-FP package, especially in terms of postpartum FP, although the overall scores for quality of care remained relatively low. This was because the quality of care scores before the intervention was introduced were lower than had been anticipated. Although all providers interviewed during the study provided services to postpartum women within their facilities, a number had not been formally trained in the MOH FP/RH training program, indicating a nationwide gap in training that needs addressing. The weaker aspects of comprehensive PNC will need increased attention as the package is rolled-out across the country over the next few years.

Postpartum women demonstrated their acceptability of the focused services package by attending for postnatal care more frequently and by stating they would recommend the services to a friend. Twice as many infants received postnatal care than their mothers, probably because the immunization schedule is fairly well established in Embu district.

Significant improvements were noted in counseling for FP and return to fertility at six weeks and a significant increase in use of LAM immediately post-delivery and at six weeks, and use of the IUD at six weeks postpartum. The most notable improvement was that women were more likely to start FP methods much earlier, within two months, probably due to more women being informed about a range of FP methods at several points in time, from ANC through to six months postpartum. Over half of all postpartum women interviewed, before and after the intervention, had ever used an FP method before, which is higher than the national average of 39 percent. All women interviewed had delivered in the maternity unit of the provincial general hospital and so were more likely to practice effective health-seeking behaviors.

Fewer women after the intervention had an unmet need for family planning i.e. they were sexually active but not using a family planning method. Only one woman in the post-intervention group lost an infant, compared with nine in the pre-intervention group, which may be attributable to the additional assessments and counseling given at 48 hours and 14 days, prompting women to return should they suspect danger signs for their infants. Despite these encouraging trends, women's understanding of when they might be able to conceive following childbirth did not change and remained low after the intervention. 
To raise the standard of care still further, the PNC-FP training package would benefit from having a clinical skills component for managing maternal and neonatal complications. The process of expanding PNC availability will require further consultation with and inclusion of key actors, which provides the opportunity for engaging with the pre-service training institutions and professional bodies to ensure institutionalization and standardization of the targeted PNC-FP training approach. Linkages with PMTCT services, the community RH strategy, as well as using FANC as the platform for strengthening the continuum of care are essential next steps.

Recommendations from the study include:

- Hold further consultations with key actors to ensure institutionalization and standardization of the revised PNC-FP package. This includes integration or linkages with PMTCT and STI services and incorporating or updating curricula of pre- service training institutions and professional bodies.

- Strengthen community linkages to continue the momentum towards creating awareness about the new the postnatal consultations and services; the need to co-opt critical actors, such as male partners and mothers in law, community leaders and health committees, community midwives, community health workers and others

- Scale up postnatal care through training of providers with focus on providing a comprehensive package of skills and care for the mother and her infant, which includes family planning, and respond to existing knowledge gaps. 


\section{REFERENCES}

Becker, S. and Ahmed, S. 2001. "Dynamics of contraceptive use and breastfeeding during the postpartum period in Peru and Indonesia", Population Studies, 55: 165-179

Borda, M. 2006. "Family Planning Needs during the First Year Postpartum”, Unpublished paper, ACCESS-FP Project, Jhpiego, Baltimore, USA.

Central Bureau of Statistics, Ministry of Health and ORC Macro. 2004. Kenya Demographic and Health Survey 2003 Calverton, Maryland: CBS, MOH and ORC Macro.

Conde- Agudelo, A., A. Rosas-Bermudez, and A. Cecila Kafury-Goeta. 2006. "Birth spacing and risk of adverse perinatal outcomes: A meta-analysis", American Medical Association vol 295, No. 151809

Department of Health, South Africa. 2003. National Committee on Confidential Enquiries into Maternal Deaths. Saving Mothers 1999-2001. DOH, Pretoria, South Africa.

Fort, A., M. Kothari, and N. Abderrahim. 2006. Postnatal care: Levels and determinants in developing countries, Calverton, Maryland: USA Macro International Inc.

Gray, G. and J. McIntyre. 2005. "HIV and pregnancy,” British Medical Journal 334: 950-953.

Kenya MOH. 2005. Safe Motherhood and Neonatal Health 'road map' (draft).

Kenya MOH. 2005. Service Provision Assessment 2004 National Coordination Agency for Population and Development, Ministry of Health, Central Bureau of Statistics and ORC Macro.

Lawn, J., S. Cousens, and J. Zupan for the Lancet Neonatal Survival Steering Team. Neonatal Survival 14 million neonatal deaths: When? Where? Why? Neonatal Survival March 2005 The Lancet p 9 - 18. London, UK.

Lewis, G. 2004. Confidential enquiries into maternal deaths: beyond the numbers: reviewing maternal deaths and complications to make pregnancy safer Geneva: World Health Organization.

McIntyre, J. 2005. “Maternal health and HIV,” Reproductive Health Matters 13(25): 129-135.

Myer, L. et al. 2005. "Focus on women: Linking HIV care and treatment with reproductive health services in the MTCT-plus initiative," Reproductive Health Matters 13(25): 136-146.

Narayanan, R, D. Cordero, S. Faillace, and T. Sanghvi. 2004. The Components of Essential Newborn Care, Basics Support for Institutionalizing Child Survival Project (BASICS II) for USAID, Arlington Virginia, USA.

Peltzer, K., Chao, L.-W. \& Dana, P. 2008. "Family planning among HIV positive and negative PMTCT clients in a resource poor setting in South Africa", AIDS and Behaviour, Feb 20[7]. 
Reynolds H., and R. Wilcher. 2006. "Best kept secret in PMTCT: Contraception to avert unintended pregnancies" AIDSlink (97): 8-9

Ross J and W. Winfrey. 2001. "Contraceptive use, Intention to Use and Unmet Need During the Extended Postpartum Period”, International Family Planning Perspectives, 27(1):20-27

Stephenson P. and P. MacDonald. 2005. Family Planning for Postpartum Women: Seizing a missed opportunity, Global Health Technical Brief: USAID, DC, USA.

Warren C., T. Ts'ukulu P. Semakaleng and M. Bosielo. 2008. Extending Prevention of Motherto-Child Transmission through Postpartum Family Planning in Lesotho, Frontiers in Reproductive Health Program, Final Report. Washington, DC: Population Council.2008

Warren C., P. Daly, L. Touré and P. Mongi. 2006. "Postnatal Care Opportunities for Africa's Newborns", in J. Lawn and K. Kerber (eds) Opportunities for Africa's newborns:

Practical data, policy and programmatic support for newborn care in Africa Partnership for Maternal, Newborn and Child Health, Cape Town, South Africa.

WHO. 1998. Postpartum care of the mother and newborn: a practical guide, Department of Reproductive Health and Research, WHO: Geneva, Switzerland.

WHO. 2005. The World Health Report 2005 - Make Every Mother and Child Count World Health Organization; Geneva, Switzerland. 


\section{Appendix 1: PNC-FP Job Aid}
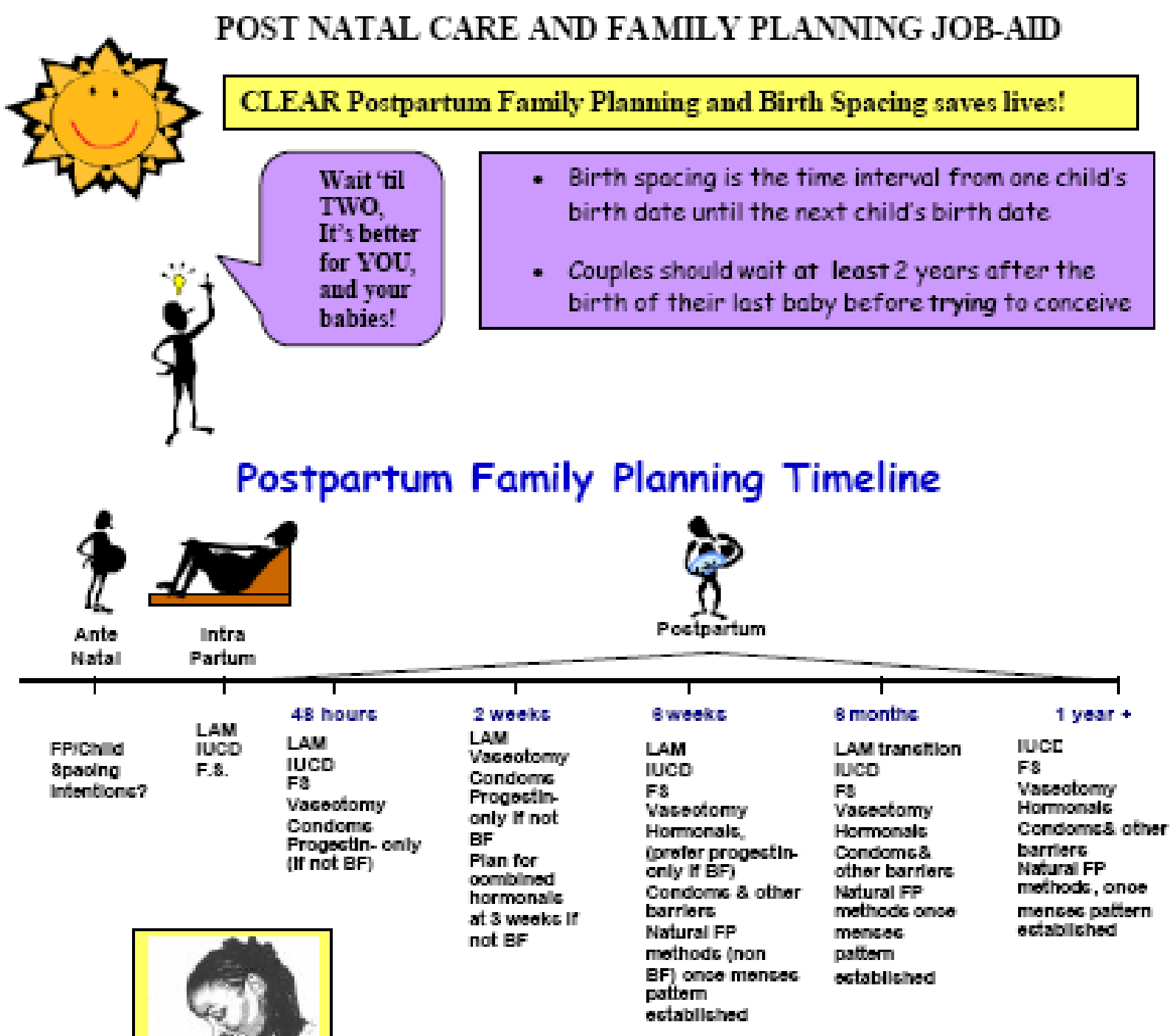

LAM 1-2-3

The Foundation of Postpartum Family Planning

Better Breastfeeding Basics

1. Ideally, begin breastfeeding immediately but not later than 30 minutes if pessible

2. Breastfeed exclusively for the first 6 months of life (no need to supplement)

3. At 6 months, continue breastfeeding with complementary feeding until age 2 years or longer where appropriate 


\section{Appendix 2}

POST PARTUM FAMILY PLANNING TRAINING OF SERVICE PROVIDERS (TOTAL = 25)

STAFF WORKING IN: MCH FP CLINIC, MATERNITY .LABOUR WARD, GYNAE -Nurse, ANC- PMTCT, HEALTH FACILITY INCHARGES, PUBLIC HEALTH OFFICER /TECHNICIAN

\begin{tabular}{|c|c|c|}
\hline HEALTH FACILITY & WORK STATION & NO. \\
\hline 1. Embu P.G Hospital & $\begin{array}{lll}\text { - } & \mathrm{MCH} / \mathrm{FP} \\
\circ & \text { Incharge } \\
\circ & \text { FP provider } \\
\circ & \text { ANC-PMTCT provider } \\
\text { - } & \text { Maternity } \\
& \text { Overall Incharge } \\
& \circ & \text { Post Natal service provider (SP) } \\
\circ & \text { Labour ward service provider } \\
\text { - Gynae } & \\
\circ & \text { Nurse SP } \\
\circ & \text { Obs/Gynae doctor } \\
\text { PHT attached to Hospital } \\
\text { TOTAL PGH }=9 \\
\end{array}$ & 3 \\
\hline 2. Karurumo Health Centre & $\begin{array}{ll}\text { - } & \text { MCH/FP } \\
\circ \quad \text { Service provider } \\
\text { - } & \text { Maternity } \\
& \circ \quad \text { Service provider } \\
\text { - } & \text { Nursing officer in Charge } \\
\text { - } & \text { PHT attached to hospital } \\
\text { TOTAL KARURUMO HC }=\mathbf{4}\end{array}$ & $\begin{array}{l}1 \\
1 \\
1 \\
1\end{array}$ \\
\hline 3. Kianjokoma Health Centre & $\begin{array}{l}\text { - } \text { MCH/FP } \\
\quad \text { O Service provider } \\
\text { - } \quad \text { Maternity } \\
\quad \text { S Service provider } \\
\text { - } \quad \text { Nursing officer in Charge } \\
\text { - PHO attached to Kianjokoma \& Kibugu HC } \\
\text { TOTAL KIANJOKOMA HC }=\mathbf{4}\end{array}$ & $\begin{array}{l}1 \\
1 \\
1 \\
1\end{array}$ \\
\hline 4. Kibugu Health Centre & $\begin{array}{l}\text { - } \mathrm{MCH} / \mathrm{FP} \\
\circ \quad \text { Service provider } \\
\text { - Maternity } \\
\circ \quad \text { Service provider } \\
\text { - Nursing officer in Charge } \\
\text { TOTAL KIBUGU } \mathbf{H C}=\mathbf{3}\end{array}$ & $\begin{array}{l}1 \\
1 \\
1\end{array}$ \\
\hline 5. Other MOH staff & $\begin{array}{ll}- & \text { PRHT\&S ( RH coordinator } \\
- & \text { DPHO } \\
- & \text { D.DPHN } \\
\text { - } & \text { Provincial Trainer } \\
\text { - } & \text { VSC }- \text { Service Provider } \\
\text { TOTAL DISTRICT \& PROVINCIAL STAFF = } 5\end{array}$ & $\begin{array}{l}1 \\
1 \\
1 \\
1 \\
1\end{array}$ \\
\hline
\end{tabular}




\section{Appendix 3: POST-PARTUM FAMILY PLANNING PRE-COURSE QUESTIONNAIRE}

\section{INSTRUCTIONS: Please circle the letter against the BEST ANSWER in the following questions:}

1. FANC is :
A. Taking women's height and weight
B. Delivery in hospital
C. Having a birth plan
D. Delivery with a skilled attendant

2. Which of the following is NOT a danger sign in pregnancy
A. Labour pains for more than 12 hours
B. Cord, arm or leg prolapsed
C. Severe swelling on the face, arms and legs
D. When the mother does not know here EDD

3. The individual birth plan ensures that the mother
A. Knows when the baby is due
B. Identifies a skilled birth attendant
C. Knows danger signs in pregnancy
D. All of the above

4. The following are risk factors for MTCT. Which one is not
A. Low maternal CD4 count
B. Normal viral load
C. Clinical staging of infections
D. Nutritional status

5. Which one of the following is not a guiding principle for the management of HIV/AIDS
A. Information about patient's condition and care should be shared with the spouse despite what the patient wishes
B. Counseling should be done at the initial visit and throughout the care
C. Confidentiality should be maintained at all times
D. HIV patients should be treated with dignity.

6. The importance of having HIV mothers access ANC services include the following except:
A. Have opportunistic infections diagnosed and treated
B. Be counseled on good feeding
C. GET ARVs
D. Does not need to use family planning contraceptive

7. Which statement is not true: Some of the challenges in providing postpartum IUD include
A. Clinical staff not willing
B. Clients are counter counseled
C. IUD's are expensive
D. Provider has no skills 
8. A woman who has had a postpartum pelvic infection more that 3 months ago can use and IUD provided?
A. She does not have intercourse
B. She douches regularly
C. She does not have a retro-verted posterior uterus
D. She is not at risk for GTI or other STD's

9. What is the advantage of PPIUD?
A. Prevent return to fertility
B. Prevent pregnancy
C. Safe and convenient
D. None of the above

10. Metal instruments used during delivery that have been decontaminated and thoroughly cleaned can be sterilized by?
A. Heat (autoclave of dry heat sterilizer)
B. Soaking them for 30 minutes in fresh $1-3 \%$ iodine solution
C. Boiling them for 20 minutes
D. Exposure to ultraviolet light for 1 hour

11. To minimize the risk of contracting HIV and hepatitis B during the cleaning process, instruments and gloves should FIRST be?
A. Rinsed in water and scrubbed with a brush before disinfecting by boiling
B. Soaked in 5\% chlorine solution for 10 minutes before cleaning
C. Rinsed in water and scrubbed with a brush before sterilization
D. Soaked overnight in $8 \%$ formaldehyde

12. Functions of vitamin A in the postpartum neonate ensure?
A. Good vision
B. Immune system
C. Prophylaxis for treatment of HIV
D. All of the above

13. What is the biggest obstacle to providing postpartum services?
A. Provider attitude
B. Time consuming
C. Lack of Skills
D. All of the above

14. When should PPFP be initiated
A. Immediately after the expulsion of the placenta
B. Within 48 hours
C. Within 6 days
D. At two weeks and then 6 weeks 
15. Medical eligibility criteria is used to:
A. Improve quality access and use of FP
B. Reduce medical barriers
C. Change misconceptions about who can and cannot use contraceptive methods
D. All of the above

16. What is the unmet need for postpartum fertility reference in Kenya
A. $92-97 \%$ of women do not want a child in 2 years after birth
B. $35 \%$ of women had their children spaced at 2 years apart or less
C. $40 \%$ of women who intend to use an FP method in the $1^{\text {st }}$ year are not using one
D. All of the above.

17. What is the best breast feeding option for the postpartum HIV mother:
A. Breastfeed all day long
B. Provide baby with cow's milk
C. Give formula
D. Exclusive breast feeding

18 Neonatal care involves counseling except:
A. Breastfeeding practices and appropriate feeding
B. Getting recommended immunizations
C. How to wean
D. Cleanliness

19. HIV infection can lead to the following except:
A. No future pregnancy
B. Spontaneous abortions and still births
C. Smaller and less healthier babies
D. HIV infected babies

20. All postpartum HIV positive women should be counseled on the following except:
A. Surgical contraception if no future pregnancy is desired
B. Safer and dual protection
C. Not to have any more pregnancies in the future
D. Available contraceptive choices. 


\section{Appendix 4: PNC-FP Orientation Workshop Schedule}

\begin{tabular}{|c|c|c|c|}
\hline TIME & DAY 1 & DAY 2 & DAY 3 \\
\hline $\begin{array}{l}8.00- \\
10: 30 \mathrm{AM}\end{array}$ & $\begin{array}{l}\text { - } \text { Introductions } \\
\text { - Participants Expectations } \\
\text { - } \text { Group Norms } \\
\text { - } \text { Gourse Schedule and Materials } \\
\text { - Administrative Issues }\end{array}$ & \begin{tabular}{|l} 
Agenda / Warm up \\
- Infant feeding \\
PPFP - Definitions \\
Unmet need MEC (WHO) \\
\\
Non - Hormonal Methods \\
Permanent Methods \\
IUD \\
Barrier Methods
\end{tabular} & $\begin{array}{l}\text { Agenda / Warm up } \\
\text { - CT with Role Plays } \\
\text { - Post Course } \\
\text { Questionnaire } \\
\text { - Develop Individual } \\
\text { Action Plans }\end{array}$ \\
\hline $\begin{array}{l}10: 30- \\
11: 00 \text { AM }\end{array}$ & TEA BREAK & TEA BREAK & TEA BREAK \\
\hline $\begin{array}{l}\text { 11:00 - } \\
1: 00 \text { AM }\end{array}$ & $\begin{array}{l}\text { - Overview of maternal mortality in } \\
\text { Kenya } \\
\text { - PPFP use and Influence on ANC in } \\
\text { Kenya } \\
\text { - Post Partum Care and the } 4 \text { Focused } \\
\text { Assessments Post Delivery }\end{array}$ & $\begin{array}{l}\text { - Role Plays } \\
\text { - Demonstrations on IUD \& Implanon } \\
\text { insertion }\end{array}$ & $\begin{array}{l}\text { - Presentation of Action } \\
\text { Plans } \\
\text { - Packing Lots }\end{array}$ \\
\hline $\begin{array}{l}\text { 1:00 - 2:00 } \\
\text { PM } \\
\end{array}$ & LUNCH & LUNCH & LUNCH \\
\hline $\begin{array}{l}2: 00-4: 00 \\
\text { PM }\end{array}$ & $\begin{array}{l}\text { - } \text { Ct PP Care and the } 4 \text { focused } \\
\text { Assessments Post Delivery } \\
\text { PMTCT } \\
\text { - Immunization }\end{array}$ & $\begin{array}{l}\text { Hormonal Methods-COC, POP, DMPA, } \\
\text { IUD, ECP, Implanon } \\
\text { - Role Plays }\end{array}$ & $\begin{array}{l}>\text { Course Evaluation } \\
>\text { Course Closing and } \\
\text { Certification }\end{array}$ \\
\hline $\begin{array}{l}\text { 4:00-4:30 } \\
\text { PM }\end{array}$ & TEA BREAK & TEA BREAK & TEA BREAK \\
\hline $\begin{array}{l}\text { 4:30 - 5:00 } \\
\text { PM }\end{array}$ & $\begin{array}{l}\text {-Summary of Day's Activities } \\
\text { - Trainers Meeting }\end{array}$ & $\begin{array}{l}\text { - Summary of Day's Activities } \\
\text { - Trainers Meeting }\end{array}$ & \\
\hline & Assignment: Day 2 Sessions & Assignment: Day 3 Sessions & \\
\hline
\end{tabular}

